\title{
An Efficient Artificial Intelligence Hybrid Approach for Energy Management in Intelligent Buildings
}

\author{
Fazli Wahid $^{1 *}$, Lokman Hakim Ismail ${ }^{2}$, Rozaida Ghazali ${ }^{{ }^{*}}$, and Muhammad Aamir ${ }^{1}$ \\ ${ }^{1}$ Faculty of Computer Science and Information Technology, Universiti Tun Hussein Onn Malaysia \\ E-mails: wahid_uomian@hotmail.com,rozaida@uthm.edu.my, amirr.khan1@gmail.com \\ ${ }^{2}$ Faculty of Civil Engineering, Universiti Tun Hussein Onn Malaysia \\ Email : lokman@uthm.edu.my \\ *Corresponding author: Fazli Wahid, Rozaida Ghazali
}

Received August 22, 2018; revised February 25, 2019; revised April 22, 2019; accepted May 30, 2019; published December 31, 2019

\begin{abstract}
Many artificial intelligence (AI) techniques have been embedded into various engineering technologies to assist them in achieving different goals. The integration of modern technologies with energy consumption management system and occupant's comfort inside buildings results in the introduction of intelligent building concept. The major aim of this integration is to manage the energy consumption effectively and keeping the occupant satisfied with the internal environment of the building. The last few couple of years have seen many applications of AI techniques for optimizing the energy consumption with maximizing the user comfort in smart buildings but still there is much room for improvement in this area. In this paper, a hybrid of two AI algorithms called firefly algorithm (FA) and genetic algorithm (GA) has been used for user comfort maximization with minimum energy consumption inside smart building. A complete user friendly system with data from various sensors, user, processes, power control system and different actuators is developed in this work for reducing power consumption and increase the user comfort. The inputs of optimization algorithms are illumination, temperature and air quality sensors' data and the user set parameters whereas the outputs of the optimization algorithms are optimized parameters. These optimized parameters are the inputs of different fuzzy controllers which change the status of different actuators according to user satisfaction.
\end{abstract}

Keywords: Energy management, user comfort, smart buildings, hybrid firefly algorithm 


\section{Background}

$\mathbf{T}_{\mathrm{h}}$ conservation system with the modern artificial intelligence technologies. The major aim of this concept is power conservation, automation, an effective management system of power and acceptable resident's satisfaction inside the building. In order to manage the power consumption inside buildings and provide user' prefered environment inside buildings, researchers working in this area have been attracted to this dimension for the last few years. The major consumers of power are commercial buildings, office buildings and residential buildings which need to be considered when developing energy management and conservation systems [1]. Since most of the time is spent by the people inside buildings, therefore, the user's comfort management inside building caanot be ignored for efficient energy management system [2]. For developing an efficient building energy management system, two phenomena must be kept under consideration. Firstly, the energy consumption must be reduced because of limited resources of pwer generation and secondly, the user comfort inside buildings should be kept according to the occupant's requirement. Since, it is a proces of targetting more than one objective at the same time, it is considered to be a multi-objective oprimization problem in which the user comfort is maximized whereas the power consumption is minimized. This concept is the main target of the work carried out in this proposed architecture for energy conservation system.

For all type of buildings, the most important issue is to efficiently reduce the consumption of power energy and provide high comfort to the occupants. The need of power energy minimization is due to the rapidly increase in energy using appliances with passage of time. This increment of energy usage become more expensive for maintaining high users comfort. But the fact is to balance the minimization of energy consumption with maximization of user comfort at the same time. Fig. 1 shows the block diagram of energy efficient building. Therefore, there is a trade-off needed between energy utilization and the achivement of user comfort. In all residential buildings, the control system is important for maintaing the minimum energy usage and maximum user comfort. For regulating the user comfort, there are three basic comfort parameters which are needed namely visual comfort, thermal comfort and air quality [6].

The internal temperature of buildings represents the thermal comfort. An auxiliary system for either cooling or heating is important in order to maintain the temperature of comfortable area in the building. For preserving the visual comfort in building, an illumination system is used whereas the air quality is kept according to the user satisfaction by using the $\mathrm{CO}_{2}$ concentration. The overall comfort of user is maintained according to his/her demand by considering all of these comforts[7], [8]. According to the literature studies, all of these three paramters are considered for controlling the comfort inside the residential buildings according to user requirments and we also considered these parameters in our reserch to fulfill user comfort demands.

The literature is rich with many energy management appraoches that are presented in order to save and reduce the energy consumption inside residential buldings. Some of these appraoches are based on conventional controlling system [9], [10], [11]. These controllers include optimal controllers, PID (Proportional Integral Derivatives) and adaptive controllers. But these conventional controllers based appraoches having many drawbacks attached to them. For example, they are quite difficult to operate and examine and less user friendly which 
cause failure in controlling the comfort parameters. In such situation [12] proposed the application of optimized fuzzy controllers for maintianing the environmental parameters for residential building.

A few other predictive control based approaches used weather prediction for inter-cooling, heating and ventilation control [13], [14]. A multi-agent based control system in which information fusion has been used, is present by [15]. The authors have also used ordered weighted averaging aggregation for controlling the indoor energy management. They focused on minimizing the energy consumption and maximizing the user comfort. There are other factors which have high influence on user comfort inside residential building such as, personal factors, social factor and inner building factors. The authors in [16] have proposed a model for understanding the relation among these complex factors while in [17], the authors presented a methodology in order to consider both the outdoor and indoor environmental factors, user comfort and energy consumption management. Different types of prediction, classification and optimization appraoches has also been proposed for different purposes for energy control and management systems. In the same way, the importance of merging information technology with green building was explored by the authors in [18]. Similarly, the authors in [19] presented a comprehensive analysis on energy management system using the smart city concept. The authors highlighted various types of challenges, issues and solutions for efficient energy management in smart cities. They classified the energy management systems of smart cities into two categories namely energy efficient solutions and energy harvesting. Both of these categories were further explored and energy frameworks, protocols and designs were highlighted.

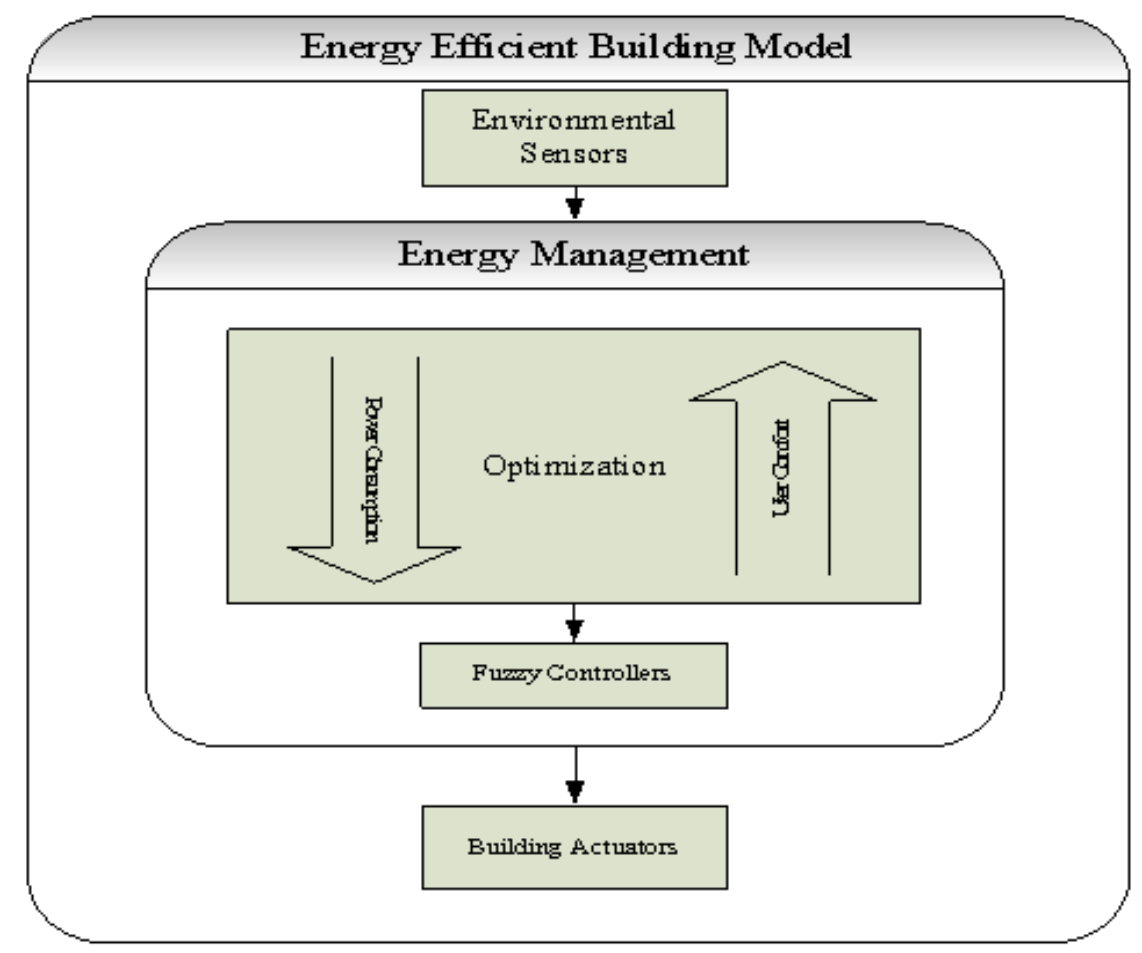

Fig. 1. Energy Management Build 


\section{Proposed Approach}

This paper proposed an optimization methodology for maximizing the user comfort and minimizing the power consumption based on a hybrid of firefly algorithm (FA) and genetic algorithm (GA) [20] and [21] optimization approach. The proposed approach is called FA-GA approach as it is the combination of two optimization algorithms and is shown in Fig. 2. Our hybrid appraoch is used for saving energy with accomplishing high user comfort at the same time. The main goal of this research is to combine the fitness function of firefly algorithm with energy consumption and user comfort index. FA-GA algorithm aims the user comfort and low energy consumption in order to maximize the first and minimize the latter.

Three parameters namely illumination, temperature and air quality from the illumination, temperature and air quality sensors are the inputs of optimization algorithm. The algorithm for optimization performs the process of optimizing the error difference between the environmental parameters and the user set parameters is reduced which result in reduced power consumption. Based on the reduced error difference, the user comfort is calculated according to the equation used for computing comfort index. This error difference is the input of fuzzy controllers used in the system. According to this error difference, the power needed for changing the status of actuators is calculated by the fuzzy controllers and the status of actuators is changed accordingly to provide user prefered values for the actuators.

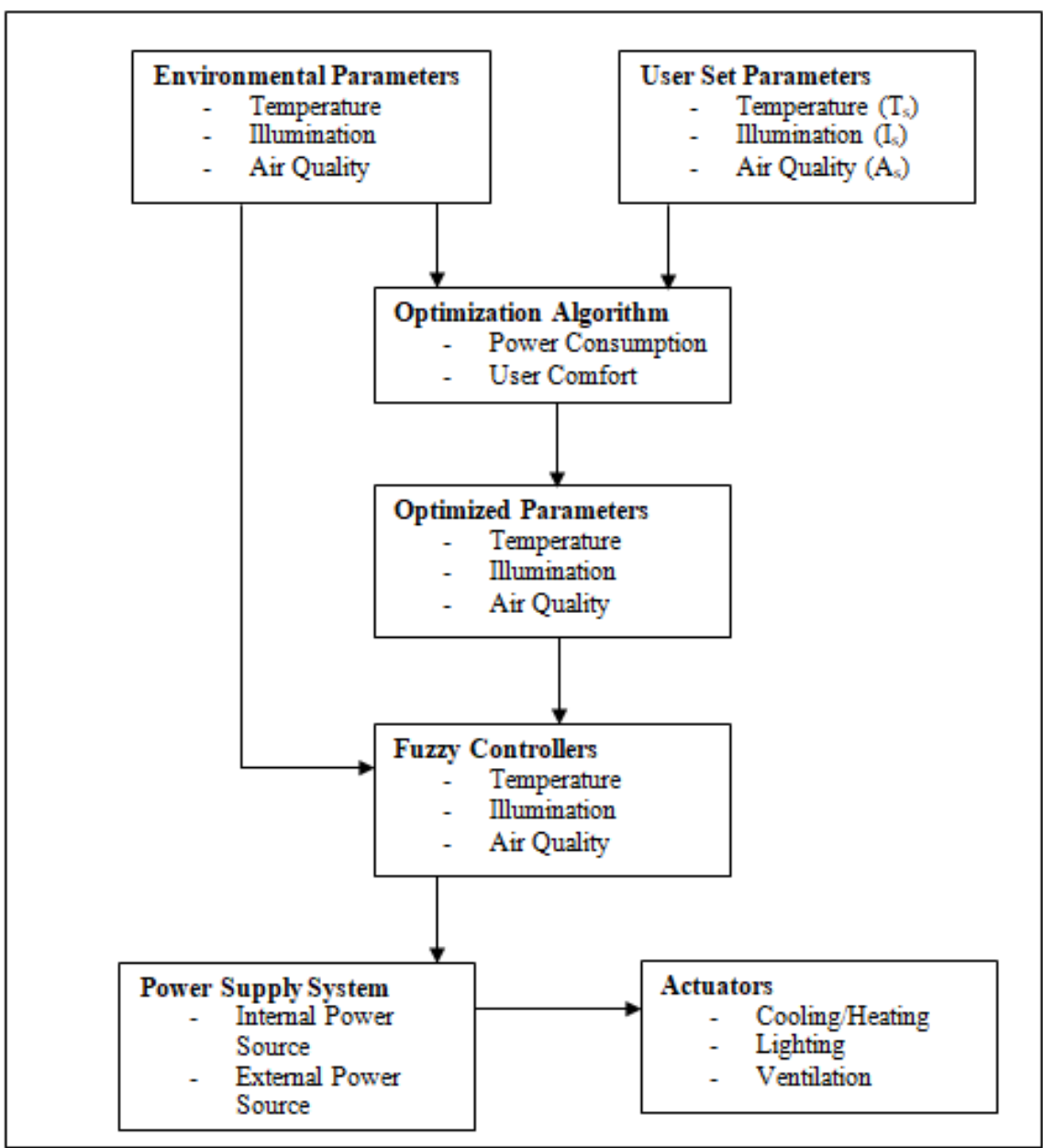

Fig. 2. Proposed approach for energy management 
As shown in the Fig. 2, the optimized and the environmental parameters enter the fuzzy controllers. In fact, when the parameters are optimized, the error difference between the optimized parameters and the environmental parameters enter the fuzzy controllers. The output of the fuzzy controllers is the power required for temperature, illumination and air control system. This required power is exported from the power supply system which has two main power sources known as internal and external power source. The power is transmitted from the power supply system to the actuators for changing the statuses.

\subsection{Proposed Al Algorithm}

The proposed AI algorithm for minimizing the energy consumption with maximizing the user comfort is a hybrid technique of two algorithms namely genetic algorithm (GA) and firefly algorithm (FA) and it has been given the name of FA-GA. In the proposed hybrid optimization model, FA is used in the start of the proposed technique and during its middle stage, GA is applied to improve the opitmization process. Firstly, the parameters of both FA and GA are initialized. Then, the population is randomly generated from the independent variables. The independent variables in this case are the illumination, temperatrue and air quality from the envirnment and also from the user. After the generation of populaiton, the fitness value of optimization function is calculated using the values of independent variables. The combination of all the independent variables make the fireflies of FA algorithm whereas the values associated with objective function make the light intensity associated with each firefly. The light intensity is used to find the best firefly from all the fireflies present in the initially generated random population. The intially randomly generated soluiton search space is updated by finding the distance of each firefly from the best firefly. Bassed on this distance, the solution search space is updated and all the fireflies are assigned new values. The step by step working mechanism of the proposed approach is shown in Fig. 3. The proposed approach is further explored in [20]. Accordingly, the location of the fireflies are updated based on the calculated fitness values. At the current stage, if the recently calculated fitness values presents a better optimized values, in that condition, the other iteration will start otherwise, some further processing is required to improve the performance of the FA. The firefly postion changing stage of standard FA depends upon the value of randomization factor used in the standard FA. If this factor is taken small, there will be poor exploitation capability of the solution search space degrading the solution quality of the algorithm. In order to resolve this issue, the GA cross over operator is embedded in the firefly position changing stage to improve the optimization mechanism by enhancing the exploitation property of the solution search space. Fig. 4 shows the pseodocode for the proposed approach. 


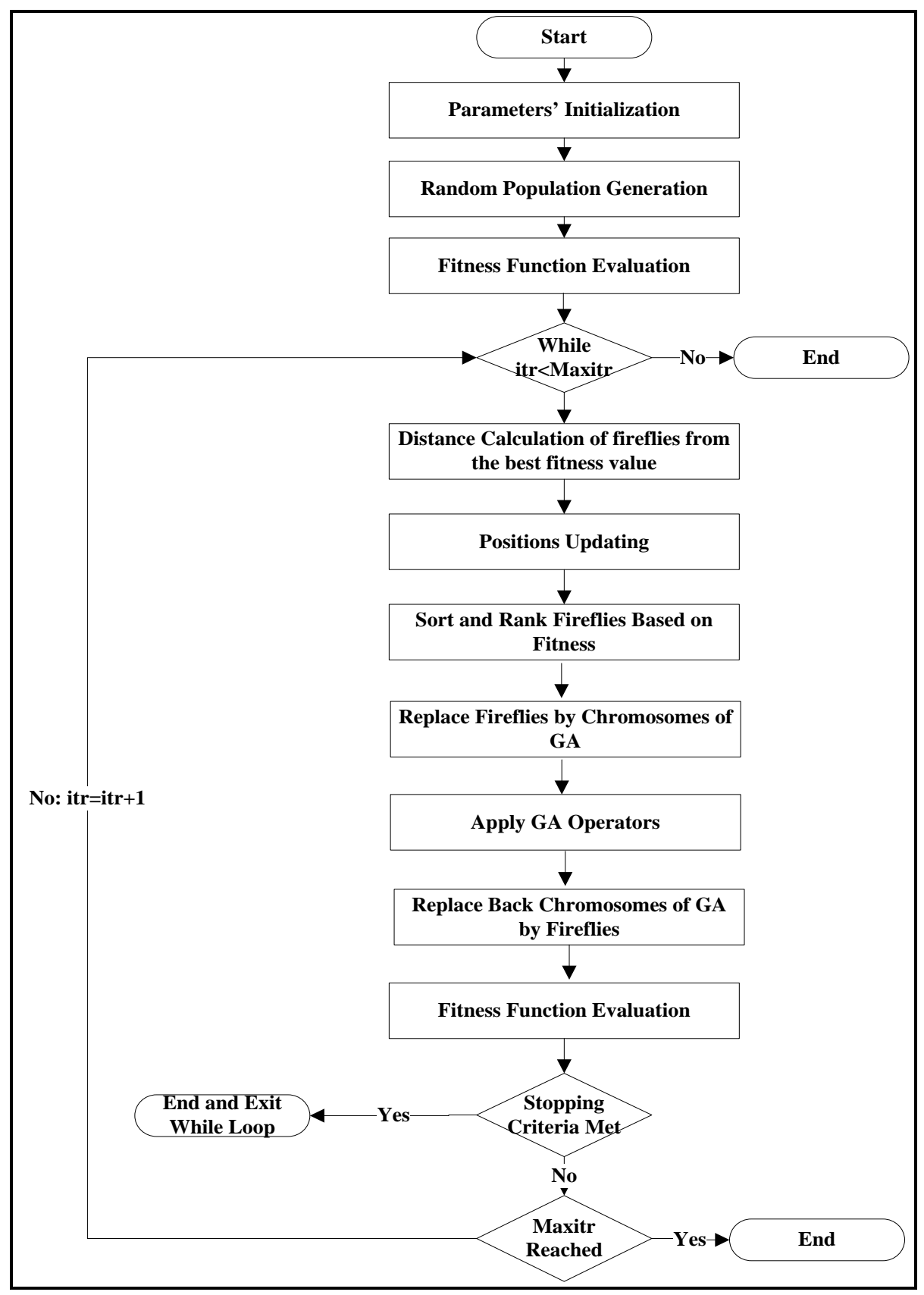

Fig. 3. Proposed AI algorithm

Embedding the crossover operator of GA in the firefly position changing stage of standard FA consists of few technical operations. The standard FA has the concept of fireflies and their light intensity whereas the standard GA has the concept of genes and chromosomes. When GA is embedded in the FA, the fireflies made up of independent variables are replaced by the chromosomes of GA made up of genes representing the independent variables. The light intensity associated with fireflis is associated with the values of chromosomes which represent the values of optimization function. In this case the optimization function is the function outlined in equation 1. After the processing is performed using crossover operator of the GA 
inside FA, the reverse process takes place in which the chromosomes are replaced by the fireflies and the values of chromosome are replaced by the light intensity of fireflies.

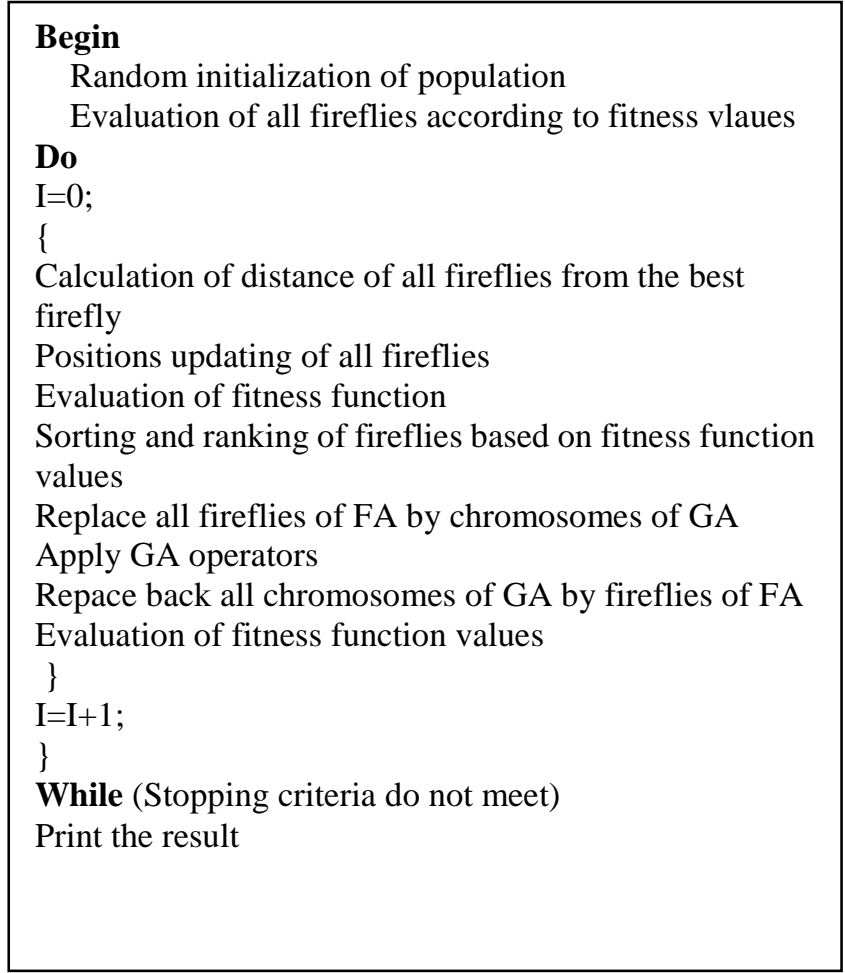

Fig. 4. Pseodocode of the proposed AI approach

\subsection{Comfort Index}

Comfort index is computed based on Equation 1 [4], [21].

$$
\mathrm{CI}=p 1\left[1-\left(e 1 / \mathrm{T}_{\mathrm{s}}\right)^{2}\right]+p 2\left[1-\left(e 2 / \mathrm{I}_{\mathrm{s}}\right)^{2}\right]+p 3\left[1-\left(e 3 / \mathrm{A}_{\mathrm{s}}\right)^{2}\right]
$$

Where CI refers to the comfort index for the user. $p 1, p 2$ and $p 3$ are user set preferences for temperature, illumination and air quality, respectively and $p 1+p 2+p 3=1$. $e 1$ represents the error difference of the optimized temperature and the environmental temperature and e2 is the error difference between the optimized illumination and environmental illumination while e3 represents the error difference between optimized air quality and environmental air quality. The highest value for $C I$ is $1 . T_{s}$ shows the user set temperature, $I_{s}$ represents the user set illumination and $\mathrm{A}_{\mathrm{s}}$ is user set air quality value. The purpose of optimization is to maximize the value of $\mathrm{CI}$ and minimize the values of $e 1, e 2$ and $e 3$. When the values of $e 1, e 2$ and $e 3$ are minimized, it will ultimately increase value of CI. Minimizing the error difference values are assocaited with energy consumption and maximizing CI values is associated with user comfort. Therefore, this phenomenon has been correlated with the statement of energy consumption minimization and user comfort maximization. Otherwise, it is single objective optimization problem in which CI value is increased by decreasing the value of e1, e2 and e3. In the equation, p1, p2 and $\mathrm{p} 3$ have been used to make the value of maximum comfort equal to 1 and it has nothing more to do with the optimizaiton process. The power consumption associated 
with e1, e2 and e3 has been computed and shown graphically and the comfort index associated with all these parameters is drawn separately which is the result of these error differences and power consumption for these three parameters.

\subsection{Fuzzy Controllers}

The idea of fuzzy was introduced by L. A. Zadeh, a professor at California University at Berkley [4]. In our proposed methodolgy, we used three fuzzy controllers which are temperature fuzzy controller, illumination fuzzy controller and the air quality fuzzy controller in order to control heating/cooling, lighting and ventilation systems, respectively.

\subsection{Coordinator}

The total power needed to control the heating/cooling, lighting and ventilation are the inputs for coordinator and the power available from the power sources is the output. The formula to calculate the overall required power is following

$$
\mathrm{TRP}=\mathrm{RP} 1+\mathrm{RP} 2+\mathrm{RP} 3
$$

Whereas the TRP represents the total required power, RP1 represents the required power for heating/cooling system, RP2 represents the required power for lighting and RP3 is the required power for ventilation.

\subsection{Actuators}

These are the devices inside buildings that need the power energy to operate. The actuators are AC (for cooling), heater (for heating), refrigerator (for cooling) and freezer (for cooling). The status of the actuators update based on the error difference between the environmental parameters and the FA-GA optimized parameters.

\section{Experimental Setup and Discussion}

We conducted all the experiments using Intel(R) core(TM) i5-3570 CPU with $3.40 \mathrm{GHz}$ procesing speed. MATLAB R2016a is used as the development environrment. For standard FA, 80 fireflies were selected as initial population. The number of iteration were 200 while the values for alpha, beta and gamma were taken as 0.2 , 2 and 1 , respectively. Values for the GA parameters were taken as 100, 200, one point cross over, 0.9 and 0.1 . For total initial population, number of maximum iterations, cross over type and cross over probability, and mutation rate, rank based method was selected. In this research work, we selected the similar combination of parameters for FA and GA. Only the number of fireflies for the proposed approach are considered as the population in GA.

\subsection{Parameters Optimization}

In the optimization algorithm, the upper and lower bound for the occupants are pre-specified in order to adjust the parameters within the range of user preferences. The upper and lower boundries of parameters for the enviroment, and the occupant's central points are read by the optimization algorithm. The main purpose of the optimization alforithm is to minimize the calculated separation value between the central set point of occupant and the parameters of the enviroment. This determind separation value is actually used for finding the 
temperature parameter's power consumption. Mathematically the error difference value is directly proportional to the power comsuption and so on. Table 1 presents the upper and lower bonds for all of the three parameters: illumination, air quality and temperature. The optimization algorithm restricts the value of enviromental parameters within the user defined range, whenever these values are getting out of the specified range.

Table. 1. Parameters Considered in the experiments with their ranges

\begin{tabular}{|l|l|l|l|l|l|l|}
\hline Parameter & Unit & $\begin{array}{l}\text { Occupant's } \\
\text { Lower } \\
\text { Boundary }\end{array}$ & $\begin{array}{l}\text { Occupant's } \\
\text { Upper } \\
\text { Boundary }\end{array}$ & $\begin{array}{l}\text { Occupant's } \\
\text { Set Central } \\
\text { Point }\end{array}$ & $\begin{array}{l}\text { Environment } \\
\text { Lower } \\
\text { Boundary }\end{array}$ & $\begin{array}{l}\text { Environment } \\
\text { Upper } \\
\text { Boundary }\end{array}$ \\
\hline Temperature & Kelvin & 68 & 78 & 73 & 60 & 85 \\
\hline Illumination & Lux & 730 & 880 & 800 & 700 & 920 \\
\hline Air Quality & $\begin{array}{l}\mathrm{CO}_{2} \\
\text { Concentration }\end{array}$ & 730 & 880 & 800 & 700 & 920 \\
\hline
\end{tabular}

\subsection{Temperature Control System}

The temperature control system consists of temperature power consumption for different approaches, temperature fuzzy controller inputs and outputs, the power computed by fuzzy controller to give it to cooling/heating system. The temperature power consumption by different approaches is shown in Fig. 5.

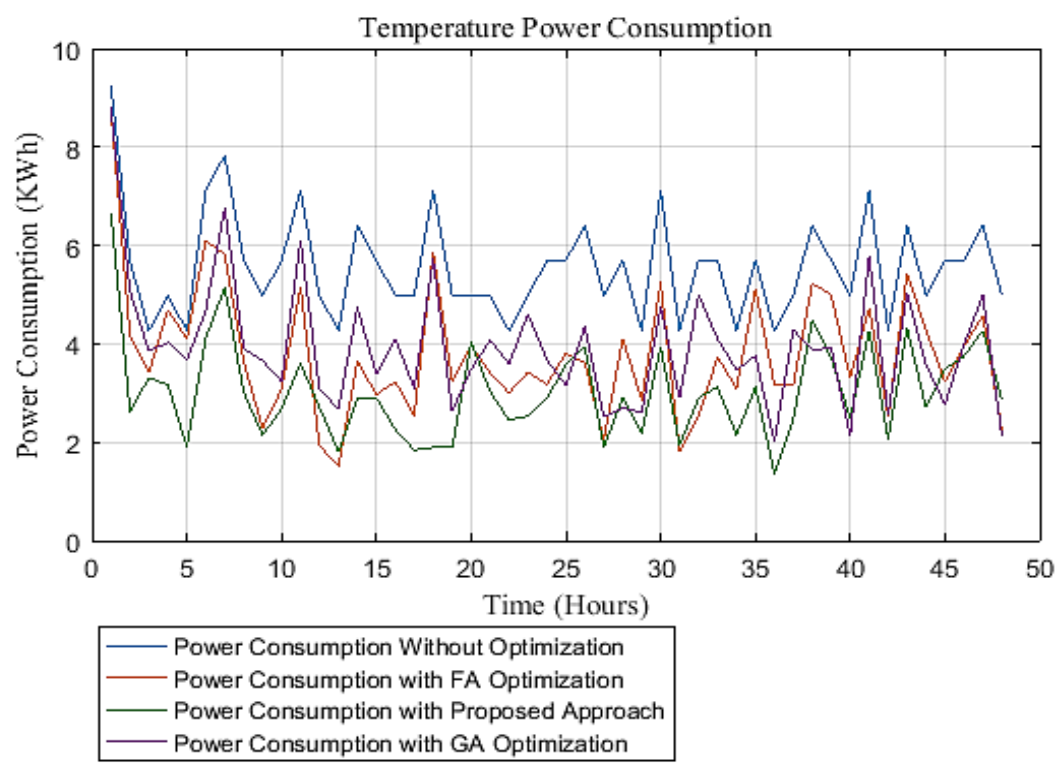

Fig. 5. Power consumption for temperature using different approaches

Fig. 5 shows the power consumption for different approaches based on the error differences found by these techniques and are shown in Table 2. The error differences shown in this table are absolute error differences. 
Table 2. Temperature Error Differences for Different Approaches

\begin{tabular}{|c|c|c|c|c|c|c|c|}
\hline $\begin{array}{c}\text { Environmental } \\
\text { Values }\end{array}$ & $\begin{array}{c}\text { User } \\
\text { Set } \\
\text { Values }\end{array}$ & $\begin{array}{c}\text { Without } \\
\text { Optimization }\end{array}$ & $\begin{array}{c}\text { With GA } \\
\text { Optimization }\end{array}$ & $\begin{array}{c}\text { With FA } \\
\text { optimization }\end{array}$ & $\begin{array}{c}\text { With PSO } \\
\text { Optimization }\end{array}$ & $\begin{array}{c}\text { With Bat } \\
\text { Algorithm } \\
\text { Optimization }\end{array}$ & $\begin{array}{c}\text { With } \\
\text { Proposed } \\
\text { Approach }\end{array}$ \\
\hline 82 & 73 & 9 & 6.1254 & 5.0876 & 7.6682 & 6.7704 & $\mathbf{5 . 5 2 3 6 8}$ \\
\hline 80 & 73 & 7 & 3.5327 & 2.8708 & 3.118 & 3.3327 & $\mathbf{2 . 6 7 1 9}$ \\
\hline 81 & 73 & 8 & 3.7985 & 5.7658 & 3.8012 & 4.8727 & $\mathbf{4 . 0 7 3 6}$ \\
\hline 79 & 73 & 6 & 3.6524 & 4.0188 & 3.7694 & 4.8812 & $\mathbf{3 . 0 7 3 5}$ \\
\hline 83 & 73 & 10 & 6.6793 & 7.3648 & 6.8056 & 8.8807 & $\mathbf{5 . 5 3 4 7}$ \\
\hline 79 & 73 & 6 & 4.0757 & 2.5438 & 3.9417 & 2.9836 & $\mathbf{2 . 7 3 2 5}$ \\
\hline 81 & 73 & 8 & 7.0163 & 3.5629 & 6.4366 & 5.1528 & $\mathbf{4 . 0 7 9 0 5}$ \\
\hline 65 & 73 & 8 & 5.7635 & 5.2451 & 5.6532 & 5.4477 & $\mathbf{4 . 3 8 7 2}$ \\
\hline 67 & 73 & 6 & 4.8736 & 4.3452 & 1.4531 & 2.3874 & $\mathbf{3 . 0 1 8 3}$ \\
\hline 65 & 73 & 8 & 5.2817 & 7.1892 & 6.4829 & 5.4872 & $\mathbf{4 . 3 8 7 2}$ \\
\hline 67 & 73 & 6 & 2.8372 & 4.4562 & 3.3854 & 2.4931 & $\mathbf{1 . 9 2 7 3}$ \\
\hline 66 & 73 & 7 & 6.0172 & 4.4512 & 5.4692 & 4.174 & $\mathbf{3 . 4 7 2 1}$ \\
\hline 64 & 73 & 9 & 5.4573 & 7.3452 & 5.3375 & 4.95623 & $\mathbf{6 . 2 8 1 2}$ \\
\hline 65 & 73 & 8 & 5.4932 & 7.0152 & 6.5678 & 3.9629 & $\mathbf{5 . 2 1 9 2}$ \\
\hline 80 & 73 & 7 & 2.9817 & 4.6479 & 5.4066 & 4.138 & $\mathbf{3 . 5 1 2 7}$ \\
\hline 83 & 73 & 10 & 8.1381 & 6.6328 & 7.5163 & 6.8816 & $\mathbf{5 . 9 8 7 3}$ \\
\hline 79 & 73 & 6 & 3.5982 & 3.5437 & 3.0365 & 4.6618 & $\mathbf{2 . 8 7 9 8}$ \\
\hline 82 & 73 & 9 & 7.0788 & 7.6348 & 6.1538 & 5.8195 & $\mathbf{6 . 0 6 2 8}$ \\
\hline 80 & 73 & 7 & 5.0179 & 6.0148 & 5.2807 & 4.4087 & $\mathbf{3 . 7 9 8 3}$ \\
\hline 81 & 73 & 8 & 3.8917 & 4.5438 & 5.1438 & 6.6288 & $\mathbf{4 . 9 0 7 2}$ \\
\hline 81 & 73 & 8 & 5.5908 & 5.5328 & 4.5109 & 3.5017 & $\mathbf{5 . 2 6 0 5}$ \\
\hline 82 & 73 & 9 & 7.0179 & 6.4327 & 6.5509 & 7.3218 & $\mathbf{5 . 9 9 6 6}$ \\
\hline
\end{tabular}

The primary goal of optimization algorithm is to decrease these error differences which ultimately reslut in lower power consumption. As shown in the table, the lowest error differnces are observed by the proposed approach of FA and GA combinely. Although, there are some fluctuations in the error differences, the overall error differences observed by the porposed modal are less than the standard GA, standard FA and the approach when no optimization algorithm is applied. The inputs of temperature fuzzy controller are these error differences and the output of the fuzzy controller is the required power for changing the status of actuators. Fig. 6 show the inputs of the temperature fuzzy controller whereas the result of the temperature fuzzy controller are presented in Fig. 7.

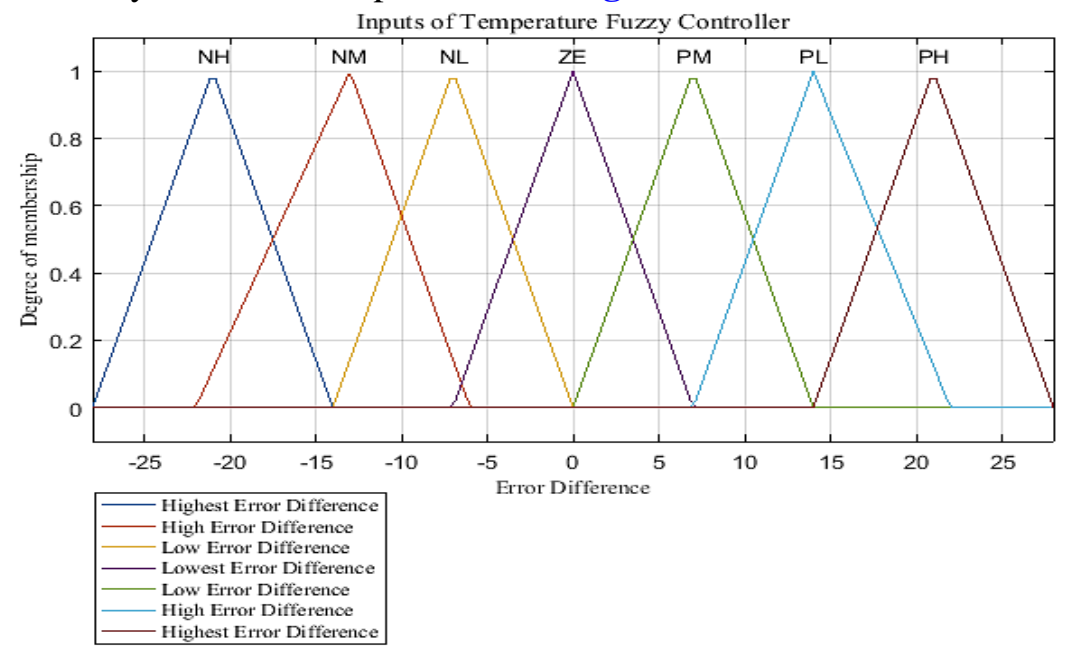

Fig. 6. Inputs of the temperature fuzzy controller 
In Fig. 6, ZE shows the lowest error difference for temperature fuzzy controller system input. As we go to the left side or right side of ZE, the error difference increases. The negative error difference also means an increase in the error difference as these values are considered as the absolute values. In the figure, both NL and PM represent the low error difference. Similarly, both the NM and PL show the high level error difference as compared to the previous values. The highest temperature error difference is observed for both $\mathrm{NH}$ and $\mathrm{PH}$.

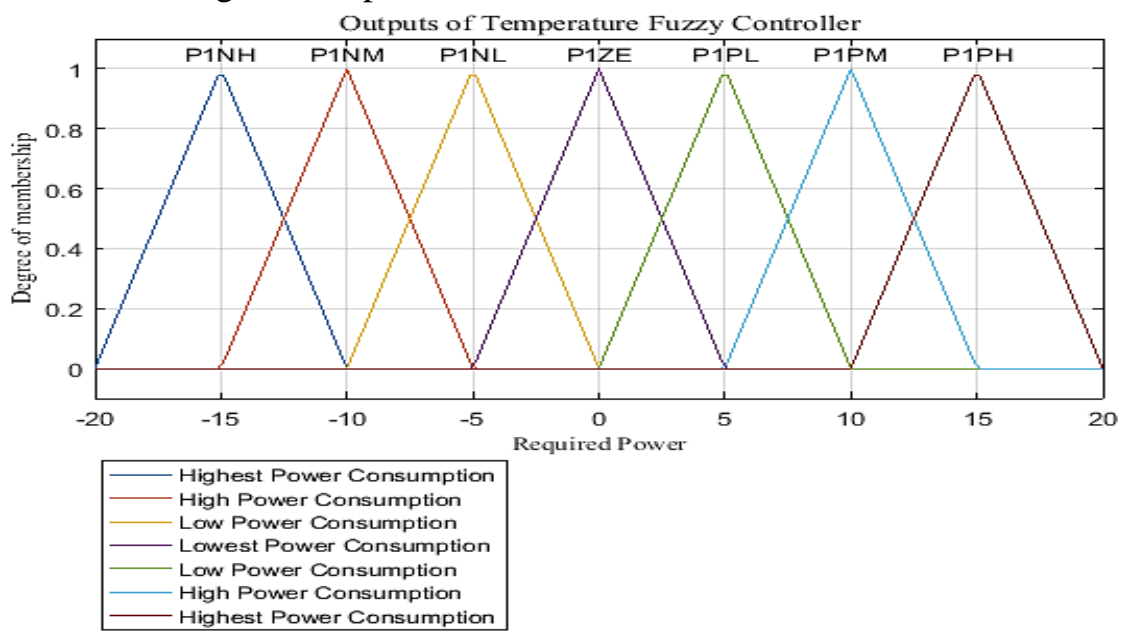

Fig. 7. Outputs of temperature fuzzy controller

Fig. 7 shows the output of temperature fuzzy controller which is associated with the inputs of temperature fuzzy controller where the eror difference between the user set temperatrue and the environmental temperature is given as inputs. The lowest power consumption is represented by P1ZE. The power consumption increases as we move from this value towards left or right side. Both P1PL and P1NL show the low power consumption. In the same way, both P1NM and P1PM show the high error difference. The highest power consumption associated with the input error difference is represented by both the $\mathrm{P} 1 \mathrm{NH}$ and $\mathrm{P} 1 \mathrm{PH}$. The degree of membership in Fig. 6 shows the values between 0 and 1 to which the values of temperature error difference is mapped. The range of error difference is quite large but these values are mapped to values between 0 and 1 for easiness to control the input status of fuzzy controller. Similarly, the power consumption in Fig. 7 is mapped to values between 0 and 1 . Instead of representing the large range of required power for temperatrue, the output status is internally represented by these values between 0 and 1.In the proposed approach, the error difference between the optimized temperature value from the optimizer and the environmental temperature is the input of the temperature fuzzy controller. While the required power for heating or cooling system is the output of the temperature. The status of the cooling/heating actuators is fuzzy controller is changed according the power provided by the fuzzy controller. The rules for temperature fuzzy controller are
If $(e 1==\mathrm{NH})$ then RP1 $=\mathrm{R} 1 \mathrm{NH}$
If $(e 1==\mathrm{NM})$ then RP1 $=\mathrm{R} 1 \mathrm{NM}$
If $(e 1==\mathrm{NL})$ then RP1 $=\mathrm{R} 1 \mathrm{NL}$
If $(e 1==\mathrm{ZE})$ then RP1 $=\mathrm{R} 1 \mathrm{ZE}$
If $(e 1==\mathrm{PL})$ then RP1 $=\mathrm{R} 1 \mathrm{PL}$
If $(e 1==\mathrm{PM})$ then RP1 $=\mathrm{R} 1 \mathrm{PM}$
If $(e 1==\mathrm{PH})$ then RP1 $=\mathrm{R} 1 \mathrm{PH}$ 
Based on the above rules, $e 1$ is the difference value between the environmental temperature and the FA-GA optimized temperature and this error difference value is the input of temperature fuzzy controller. Accroding to this error difference, the temperature fuzzy controller produces the energy as a result represented by RP1 (required power 1) to provide it to the cooling/heating actuators.

As shown in the inputs and outputs figures of fuzzy controllers, as the input error differences increase as identified in the figure, the power consumption in the output fuzzy controller rules decrease. Keeping the inputs outputs relationship in the temperature fuzzy controller, an example of input and output for all the considered approaches is shown in Fig. 8.

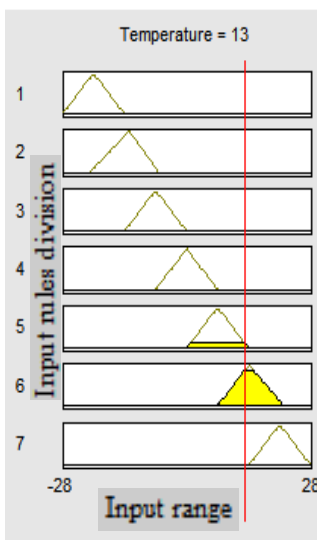

(a)
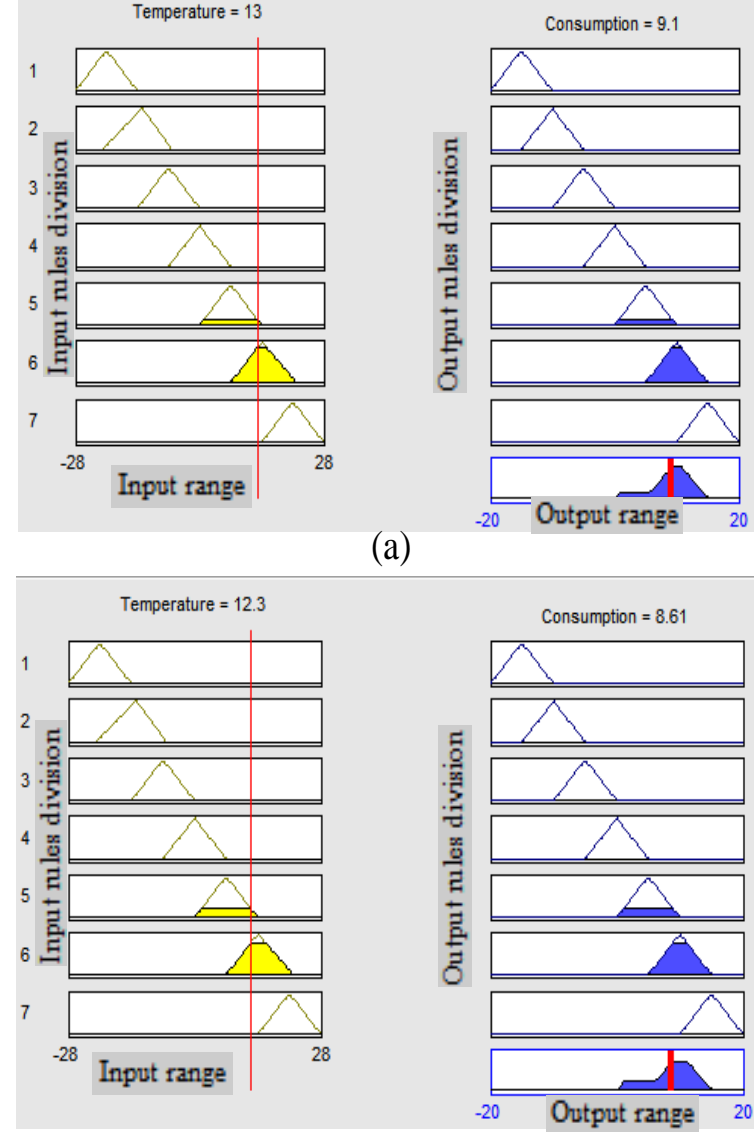

(c)

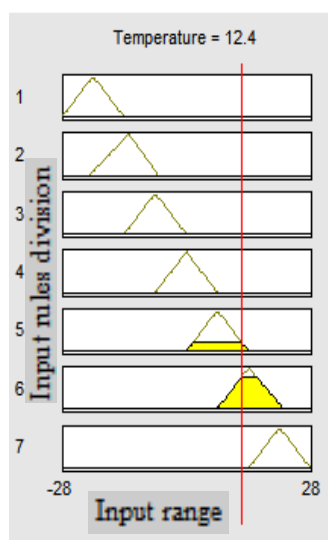

(b)
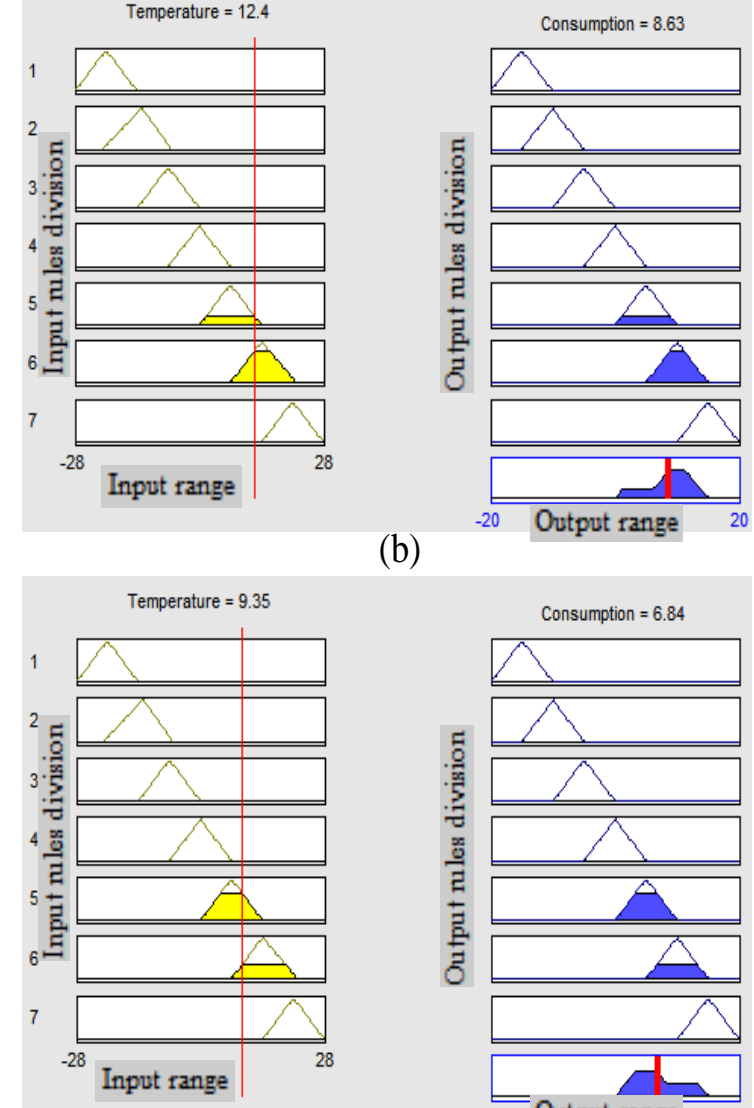

(d)

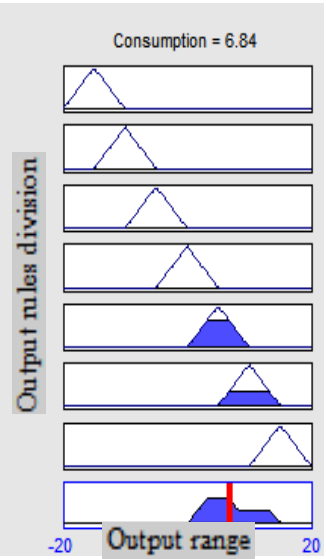

Fig. 8. Temperature fuzzy controller rule applied for a single value (a) Consumption without optimization (b) With GA optimization (c) With FA optimization (d) With prooposed approach optimization

\subsection{Illumination Control System}

The illumination control system consist of a few major components that are, illumination power consumption of different approaches, illumination fuzzy controller inputs and outputs, the power computed by fuzzy controller to give it to lighting system. Fig. 9 shows illumination power consumption by different approaches. 


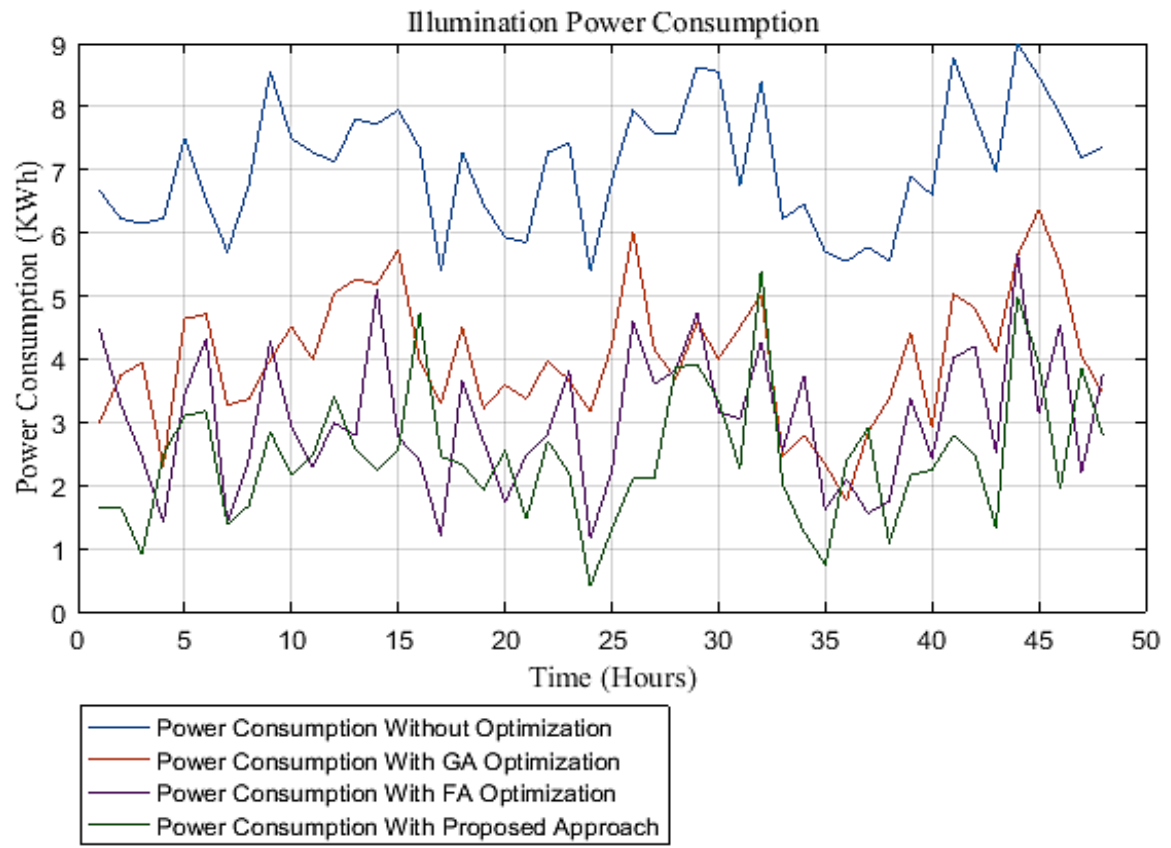

Fig. 9. Power consumption for illumination using different approaches

Fig. 10 Show the inputs of illumination fuzzy controller whereas the outputs of illumination fuzzy controller are shown in Fig. 11. The inputs and outputs of the illumination fuzzy controller are based on error differences for different approaches shown in Table 3.

Table 3. Illumination Error Differences for Different Approaches

\begin{tabular}{|r|r|c|c|c|r|r|c|}
\hline $\begin{array}{c}\text { Environmental } \\
\text { Values }\end{array}$ & $\begin{array}{c}\text { User } \\
\text { Set } \\
\text { Values }\end{array}$ & $\begin{array}{c}\text { Without } \\
\text { Optimization }\end{array}$ & $\begin{array}{c}\text { With GA } \\
\text { Optimization }\end{array}$ & $\begin{array}{c}\text { With FA } \\
\text { optimization }\end{array}$ & $\begin{array}{c}\text { With PSO } \\
\text { Optimization }\end{array}$ & $\begin{array}{c}\text { With Bat } \\
\text { Algorithm } \\
\text { Optimization }\end{array}$ & $\begin{array}{c}\text { With } \\
\text { Proposed } \\
\text { Approach }\end{array}$ \\
\hline 906 & 800 & 106 & 80.3185 & 61.2468 & 56.6179 & 67.6807 & $\mathbf{2 8 . 1 6 7 4}$ \\
\hline 901 & 800 & 101 & 55.2362 & 48.0873 & 42.6084 & 59.6735 & $\mathbf{2 8 . 2 5 3 9}$ \\
\hline 901 & 800 & 101 & 49.2169 & 51.0795 & 59.6985 & 43.7985 & $\mathbf{5 1 . 5 2 8 1}$ \\
\hline 915 & 800 & 115 & 61.1644 & 63.0693 & 53.6981 & 76.629 & $\mathbf{5 2 . 2 2 8 6}$ \\
\hline 914 & 800 & 114 & 53.3861 & 42.2361 & 65.7919 & 54.7896 & $\mathbf{4 4 . 6 0 8 6}$ \\
\hline 890 & 800 & 90 & 60.0693 & 40.6694 & 28.6975 & 41.5981 & $\mathbf{3 0 . 2 6 7 5}$ \\
\hline 912 & 800 & 112 & 66.9505 & 57.0023 & 51.9357 & 41.8901 & $\mathbf{7 2 . 0 3 2 7}$ \\
\hline 717 & 800 & 83 & 32.8951 & 34.0527 & 32.9306 & 34.6736 & $\mathbf{2 6 . 9 4 7 1}$ \\
\hline 714 & 800 & 86 & 37.3497 & 49.7731 & 35.7843 & 25.38969 & $\mathbf{1 6 . 8 7 2 4}$ \\
\hline 724 & 800 & 76 & 31.0981 & 21.5521 & 27.4065 & 25.3095 & $\mathbf{9 . 8 7 2 1}$ \\
\hline 726 & 800 & 74 & 23.4981 & 28.0117 & 25.0775 & 35.5403 & $\mathbf{3 1 . 8 2 6 2}$ \\
\hline 723 & 800 & 77 & 37.8915 & 20.7318 & 26.0088 & 33.4064 & $\mathbf{3 8 . 7 2 1 4}$ \\
\hline 726 & 800 & 74 & 45.0271 & 23.3362 & 16.4418 & 23.8866 & $\mathbf{1 4 . 5 8 7 1}$ \\
\hline 708 & 800 & 92 & 58.9261 & 45.0053 & 36.8815 & 39.0562 & $\mathbf{2 8 . 8 7 1 6}$ \\
\hline 712 & 800 & 88 & 38.8024 & 32.4492 & 29.6403 & 39.7742 & $\mathbf{2 9 . 8 9 1 6}$ \\
\hline 917 & 800 & 117 & 67.1277 & 53.6239 & 69.5281 & 75.5933 & $\mathbf{3 7 . 2 1 8 5}$ \\
\hline 905 & 800 & 105 & 64.1791 & 55.9901 & 56.4482 & 65.6125 & $\mathbf{3 3 . 1 5 3 9}$ \\
\hline 893 & 800 & 93 & 54.9053 & 33.4868 & 59.6508 & 45.5127 & $\mathbf{1 7 . 6 5 7 5}$ \\
\hline 920 & 800 & 120 & 75.0974 & 75.5507 & 75.6624 & 70.5347 & $\mathbf{6 6 . 4 3 7 6}$ \\
\hline 913 & 800 & 113 & 84.9072 & 41.9052 & 52.6155 & 73.5046 & $\mathbf{5 2 . 5 3 8 5}$ \\
\hline 905 & 800 & 105 & 73.0962 & 60.5982 & 60.5427 & 43.5166 & $\mathbf{2 6 . 0 6 3 6}$ \\
\hline 896 & 800 & 96 & 54.1068 & 29.3381 & 46.1185 & 51.1085 & $\mathbf{5 1 . 5 5 0 5}$ \\
\hline 898 & 800 & 91 & 56.1873 & 29.5079 & 46.9484 & 48.3323 & $\mathbf{1 7 . 3 6 7 3}$ \\
\hline & & & & & & \\
\hline
\end{tabular}


The error difference between the optimized illumination from the FA-GA optimizer and the environmental illumination is input to the illumination fuzzy controller while the required power for lighting system is the output of the illumination fuzzy controller. The current status of the Lighting actuators updates based the power provided by the fuzzy controller. Following are the major rules for illumination fuzzy controller.

If $(e 2==\mathrm{HS})$ then RP2 $=$ R2HS

If $(e 2==\mathrm{MS})$ then RP2 $=$ R2MS

If $(e 2==\mathrm{BS})$ then RP2 $=\mathrm{R} 2 \mathrm{BS}$

If $(e 2==\mathrm{OK})$ then $\mathrm{RP} 2=\mathrm{R} 2 \mathrm{OK}$

If $(e 2==\mathrm{SH})$ then $\mathrm{RP} 2=\mathrm{R} 2 \mathrm{SH}$

If $(e 2==\mathrm{H})$ then $\mathrm{RP} 2=\mathrm{R} 2 \mathrm{H}$

In which $e 2$ represents the sepration value between the FA-GA optimized illumination and the environmental illumination. This error difference is the input to the illumination fuzzy controller. The illumination fuzzy controller generates the energy based on this error difference, as a result which is represented by RP2 (required power 2) to provide it to the lighting system.

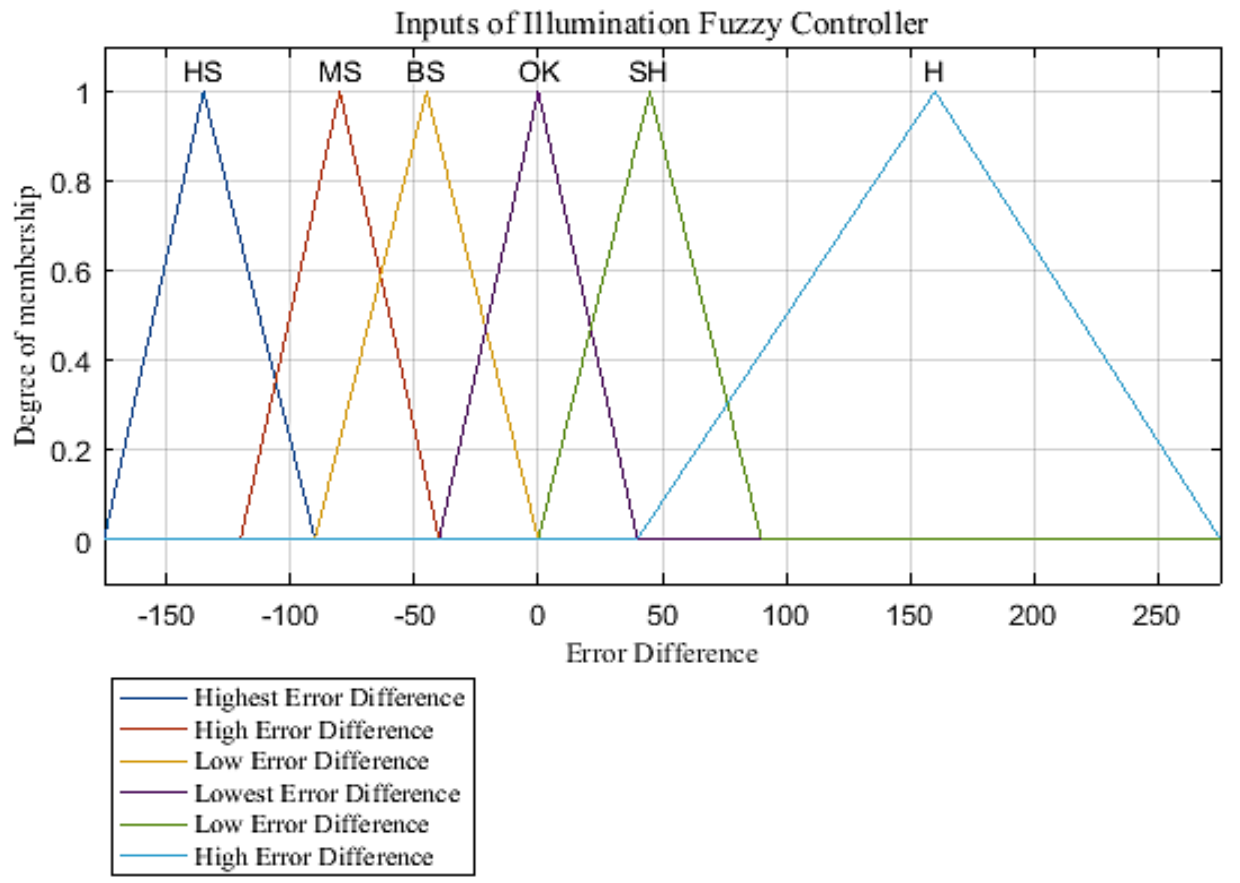

Fig. 10. Inputs of illumination fuzzy controller

In Fig. 10, OK shows the lowest error difference for illumination fuzzy controller system input. As we go to the left side or right side of OK, the error difference increases. The negative error difference also means an increase in the error difference as these values are considered as the absolute values. In the figure, both SH and BS represent the low error difference. Similarly, both the MS and $\mathrm{H}$ show the high level error difference as compared to the previous values. The highest illumination error difference is observed for HS. The degree of membership in Fig. 9 shows the values between 0 and 1 to which the values of illumination error difference is mapped. The range of error difference is quite large but these values are mapped to values between 0 and 1 for easiness to control the input status of fuzzy controller. Similarly, the power consumption in Fig. 10 is mapped to values between 0 and 1. Instead of representing 
the large range of required power for illumination, the output status is internally represented by these values between 0 and 1 .

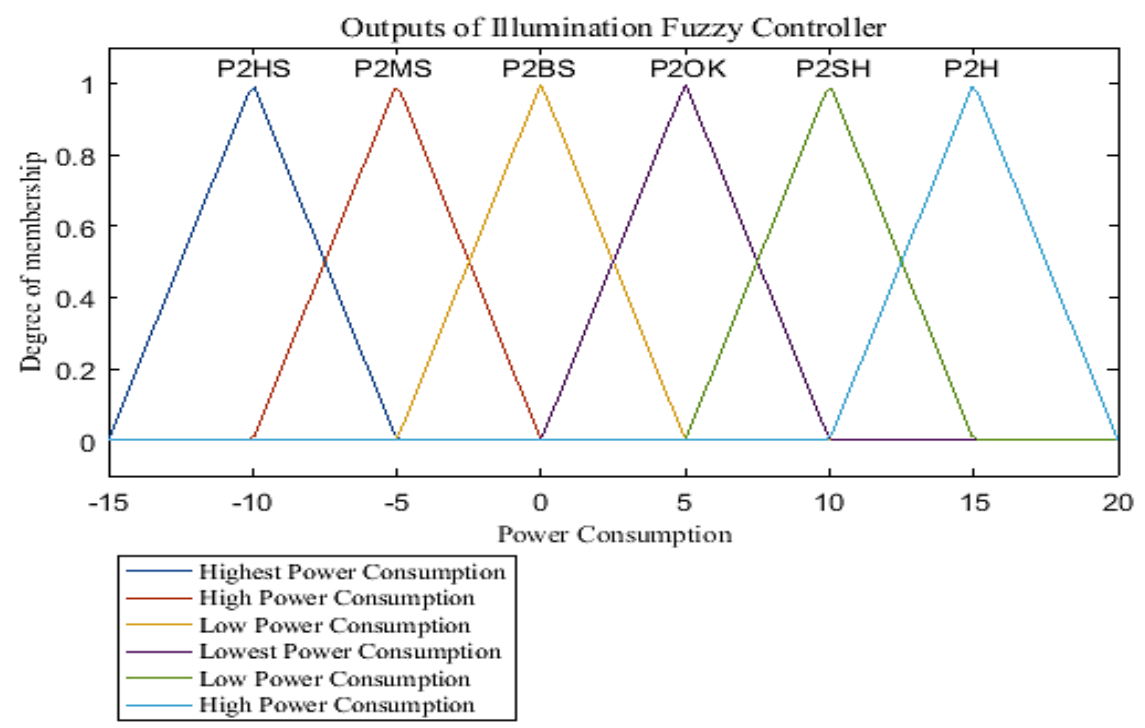

Fig. 11. Outputs of illumination fuzzy controller

An example of power provided by illumination fuzzy controller to the lighting actuator is shown in Fig. 12. The figure shows the example input and corresponding output for each of the optimization approaches considered.

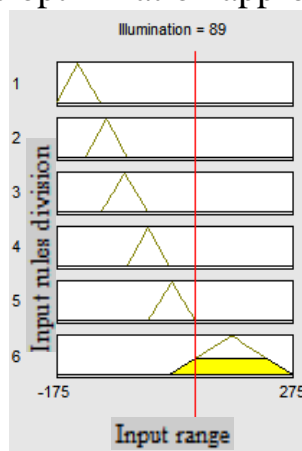

(a)

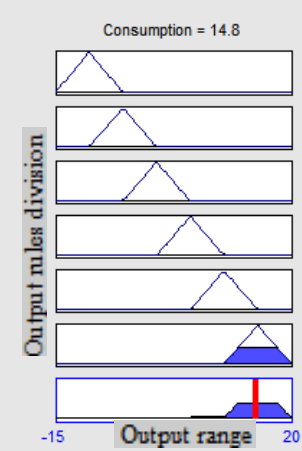

Illumination $=59.8$

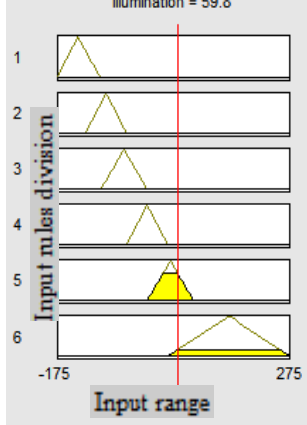

(c)

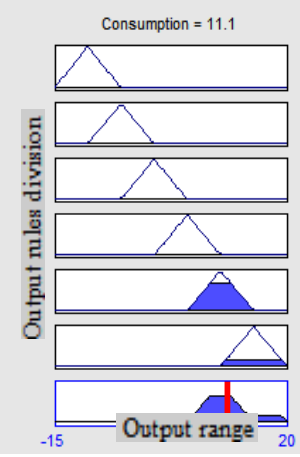

Fig. 12. Illumination fuzzy controller rule applied for a single value (a) Consumption without optimization (b) With GA optimization (c) With FA optimization (d) With prooposed approach optimization

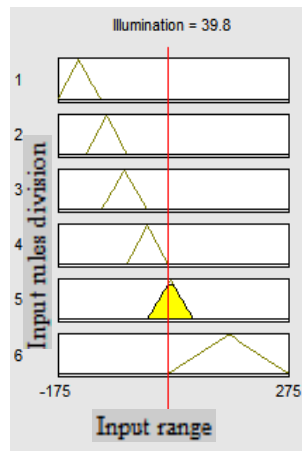

(b)
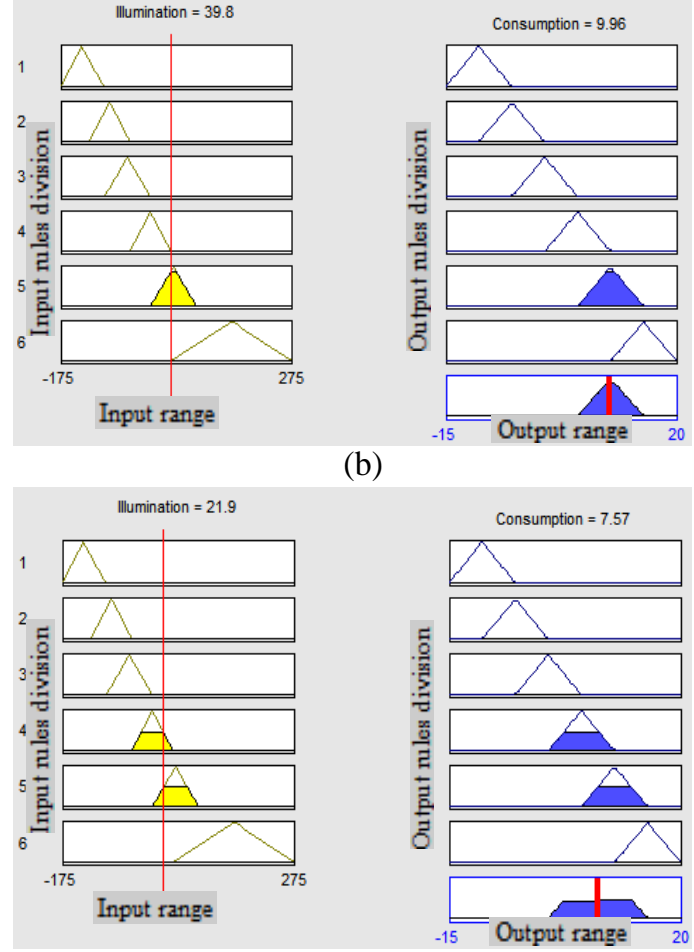

(d) out 
Fig. 11 shows the output of illumination fuzzy controller which is associated with the inputs of illumination fuzzy controller where the eror difference between the user set illumination and the environmental illumination is given as inputs. The lowest power consumption is represented by P2OK. The power consumption increases as we move from this value towards left or right side. Both P2BS and P2SH show the low power consumption. In the same way, both $\mathrm{P} 2 \mathrm{H}$ and P2MS show the high power consumption. The highest power consumption associated with the input error difference is represented by P2HS.

\subsection{Air Quality Control System}

The air quality control system is composed of different components e.g. the power consumption computation, the air quality fuzzy controllers and the ventilation system power consumption system. Fig. 13 Shows the energy consumed by different approaches considered in experimentation. The energy consumed by different optimization techniques is based on error differences calculated by these approaches and are shown in Table 4. The inputs and outputs of air quality fuzzy controller are shown in Fig. 14 and Fig. 15, respectively. Based on the inputs and outputs of the air quality fuzzy controller, a sample output power is shown in Fig. 16.

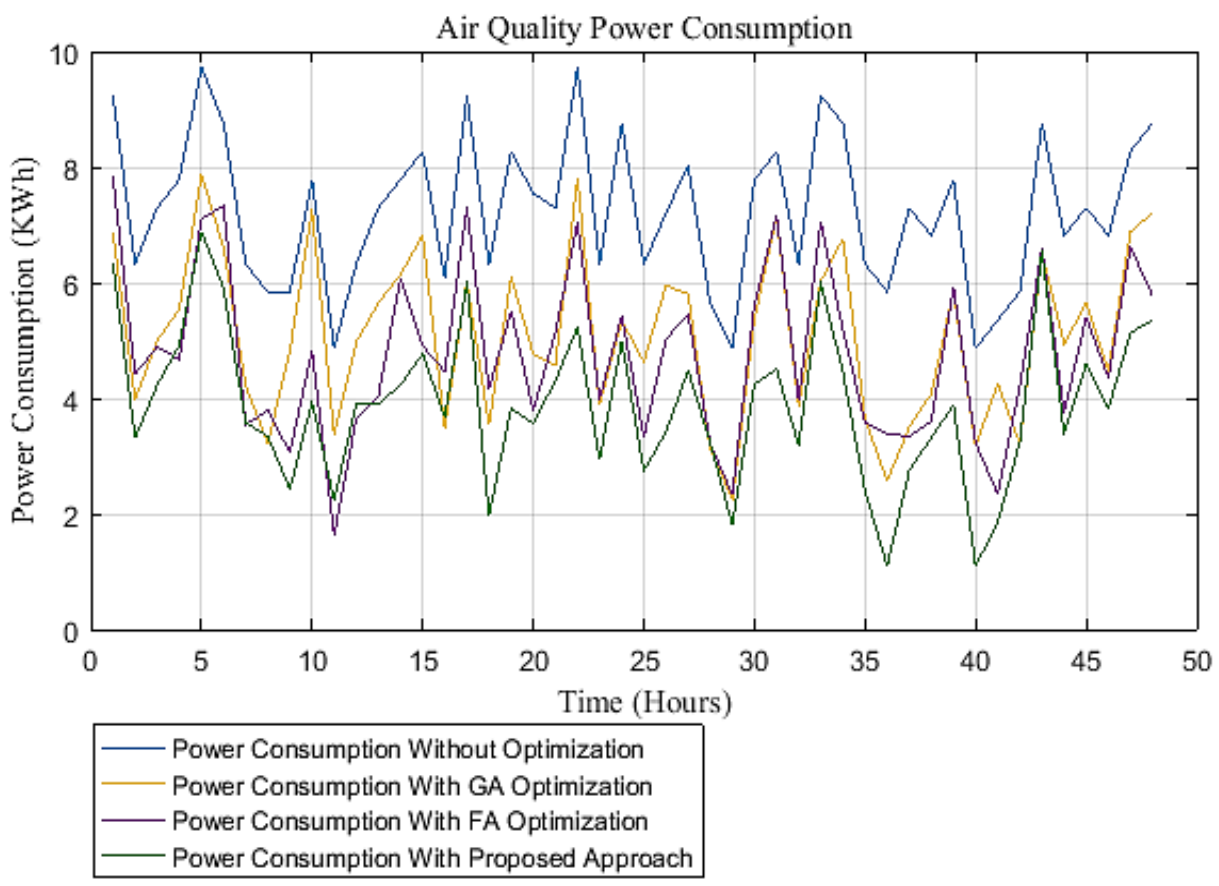

Fig. 13. Power consumption for air quality using different approaches 
Table 4. Air Quality Error Differences for Different Approaches

\begin{tabular}{|c|c|c|c|c|c|c|c|}
\hline $\begin{array}{c}\text { Environmental } \\
\text { Values }\end{array}$ & $\begin{array}{c}\text { User } \\
\text { Set } \\
\text { Values }\end{array}$ & $\begin{array}{c}\text { Without } \\
\text { Optimization }\end{array}$ & $\begin{array}{c}\text { With GA } \\
\text { Optimization }\end{array}$ & $\begin{array}{c}\text { With FA } \\
\text { optimization }\end{array}$ & $\begin{array}{c}\text { With PSO } \\
\text { Optimization }\end{array}$ & $\begin{array}{c}\text { With Bat } \\
\text { Algorithm } \\
\text { Optimization }\end{array}$ & $\begin{array}{c}\text { With } \\
\text { Proposed } \\
\text { Approach }\end{array}$ \\
\hline 930 & 800 & 130 & 95.1873 & 68.5079 & 84.4438 & 80.5617 & $\mathbf{5 6 . 3 6 7 3}$ \\
\hline 948 & 800 & 148 & 122.319 & 103.247 & 97.6518 & 114.195 & $\mathbf{7 0 . 1 6 7 4}$ \\
\hline 965 & 800 & 165 & 119.236 & 112.087 & 124.516 & 119.514 & $\mathbf{9 2 . 2 5 3 9}$ \\
\hline 916 & 800 & 116 & 64.2169 & 66.0795 & 66.5472 & 78.5647 & $\mathbf{6 6 . 5 2 8 1}$ \\
\hline 900 & 800 & 100 & 46.1644 & 48.0693 & 60.5545 & 52.6266 & $\mathbf{3 7 . 2 2 8 6}$ \\
\hline 960 & 800 & 160 & 110.127 & 115.602 & 102.516 & 110.776 & $\mathbf{8 7 . 2 3 5}$ \\
\hline 970 & 800 & 170 & 147.107 & 147.537 & 142.562 & 128.516 & $\mathbf{9 2 . 5 2 3 6}$ \\
\hline 930 & 800 & 130 & 79.3671 & 81.5016 & 81.5336 & 109.516 & $\mathbf{6 5 . 5 1 2 6}$ \\
\hline 610 & 800 & 190 & 123.9037 & 144.9483 & 153.4765 & 161.4837 & $\mathbf{1 2 3 . 3 8 7 3}$ \\
\hline 620 & 800 & 180 & 138.9098 & 106.3763 & 119.3874 & 121.4763 & $\mathbf{9 1 . 4 7 6 4}$ \\
\hline 670 & 800 & 130 & 74.7846 & 73.7363 & 68.3564 & 78.5746 & $\mathbf{4 9 . 4 6 5 4}$ \\
\hline 680 & 800 & 120 & 52.8475 & 69.4764 & 67.5847 & 52.5764 & $\mathbf{2 2 . 4 6 5 4}$ \\
\hline 650 & 800 & 150 & 71.8946 & 68.763 & 81.4746 & 69.3654 & $\mathbf{5 6 . 4 7 6 4}$ \\
\hline 660 & 800 & 140 & 83.8934 & 73.9837 & 73.5746 & 81.3546 & $\mathbf{6 8 . 2 8 7 2}$ \\
\hline 640 & 800 & 160 & 120.5674 & 121.8362 & 113.4355 & 104.4763 & $\mathbf{7 9 . 7 6 3}$ \\
\hline 900 & 800 & 100 & 65.216 & 66.1627 & 52.5107 & 63.6346 & $\mathbf{2 2 . 5 2 3 6}$ \\
\hline 910 & 800 & 110 & 87.4237 & 48.2365 & 74.5237 & 62.4536 & $\mathbf{3 8 . 2 6 3 7}$ \\
\hline 920 & 800 & 120 & 66.1746 & 86.6127 & 75.5236 & 68.5264 & $\mathbf{6 6 . 6 2 3 7}$ \\
\hline 980 & 800 & 180 & 134.165 & 135.525 & 116.513 & 140.412 & $\mathbf{1 3 4 . 5 3 2}$ \\
\hline 940 & 800 & 140 & 101.377 & 77.2737 & 99.5254 & 91.4154 & $\mathbf{6 9 . 5 2 3 6}$ \\
\hline 950 & 800 & 150 & 116.327 & 111.163 & 89.4524 & 110.616 & $\mathbf{9 4 . 5 2 3 6}$ \\
\hline 940 & 800 & 140 & 92.1276 & 89.4236 & 103.452 & 84.5524 & $\mathbf{7 8 . 5 3 4 6}$ \\
\hline 970 & 800 & 170 & 141.463 & 136.106 & 124.413 & 119.451 & $\mathbf{1 0 5 . 5 3 2}$ \\
\hline 980 & 800 & 130 & 95.1873 & 68.5079 & 129.563 & 135.49 & $\mathbf{5 6 . 3 6 7 3}$ \\
\hline
\end{tabular}
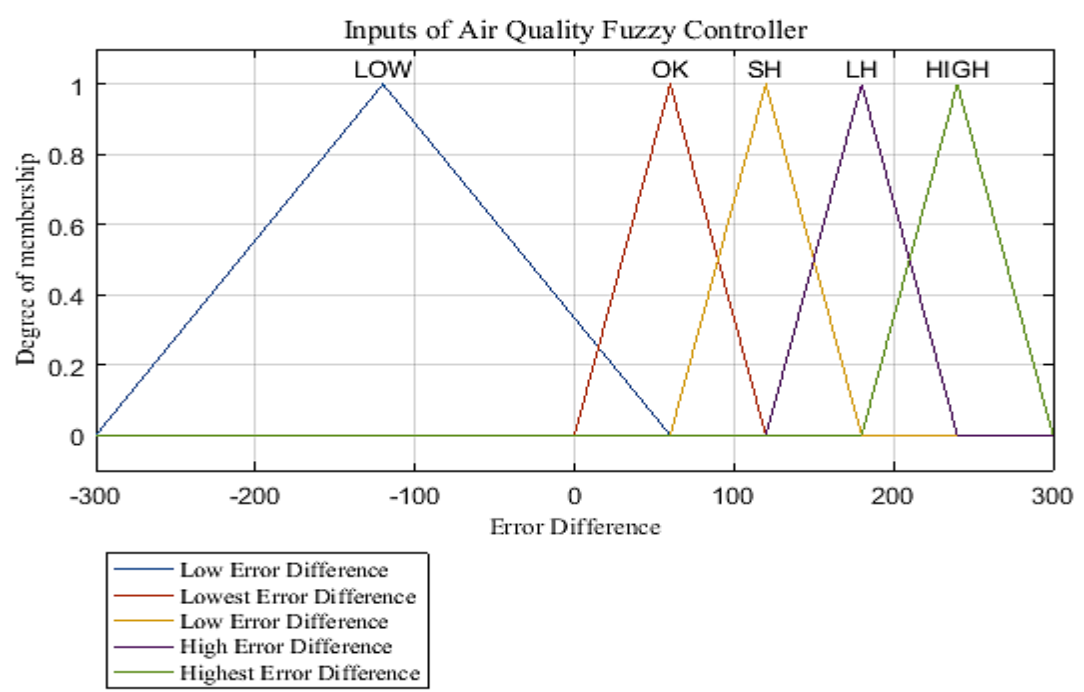

Fig. 14. Inputs of air quality fuzzy controller 


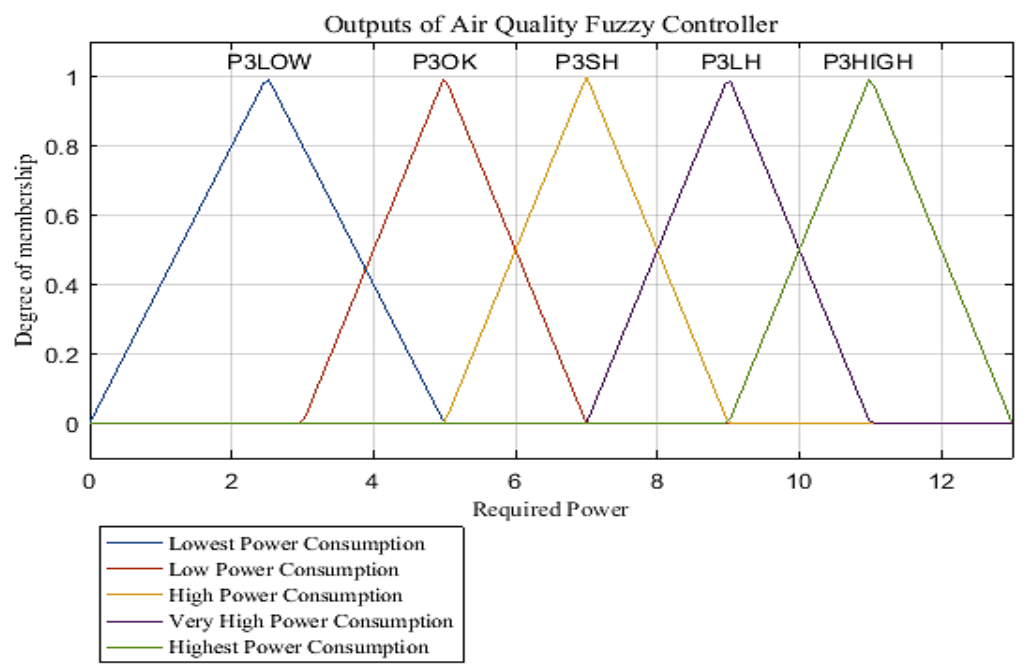

Fig. 15. Outputs of air quality fuzzy controller

In Fig. 14, OK shows the lowest error difference for air quality fuzzy controller system input. As we go to the left side or right side of $\mathrm{SH}$, the error difference increases. The negative error difference also means an increase in the error difference as these values are considered as the absolute values. In the figure, both LOW and $\mathrm{SH}$ represent the low error difference. Similarly, LH shows the high level error difference as compared to the previous values. The highest air quality error difference is observed for HIGH value. Fig. 15 shows the output of air quality fuzzy controller which is associated with the inputs of air quality fuzzy controller where the eror difference between the user set air quality and the environmental air quality is given as inputs. The lowest power consumption is represented by P3LOW. The power consumption increases as we move from this value towards right side. $\mathrm{P} 3 \mathrm{OK}$ shows low power consumption and P3SH shows high power consumption. In the same way, both P3LH and P3HIGH show very high power consumption and the highest power consumption, respectively.

The degree of membership in Fig. 14 shows the values between 0 and 1 to which the values of air quality error difference is mapped. The range of error difference is quite large but these values are mapped to values between 0 and 1 for easiness to control the input status of fuzzy controller. Similarly, the power consumption in Fig. 15 is mapped to values between 0 and 1 . Instead of representing the large range of required power for air quality, the output status is internally represented by these values between 0 and 1 . The separation value between the environmental air quality and the optimized air quality from the optimizer is the input of the air quality fuzzy controller and the required power for ventilation system is the output. The status of the ventilation actuators is updated according the separation value between the FA-GA optimized parameters and the real environmental parameters in which the output of the ventilation fuzzy controller is the required power for the actuator status. Following are the fuzzy rules for air quality fuzzy controller.

If $(e 3==\mathrm{LOW})$ then RP3 $=$ R3LOW

If $(e 3==\mathrm{OK})$ then $\mathrm{RP} 3=\mathrm{R} 3 \mathrm{OK}$

If $(e 3==\mathrm{SH})$ then RP3 $=$ R3SH

If $(e 3==\mathrm{LH})$ then RP3 $=$ R3LH

If $(e 3==\mathrm{HIGH})$ then RP3 $=$ R3HIGH 
Where $e 3$ represents the separation value between the real environmental air quality and the optimized air quality based on FA-GA futhermore this vallue for error difference is the input of air quality fuzzy controller. On the bases of this error difference value, the energy generated by the fuzzy controller for air quality is the output which is represented by RP3 (required power 3 ) in order to provide it for the ventilation system control.

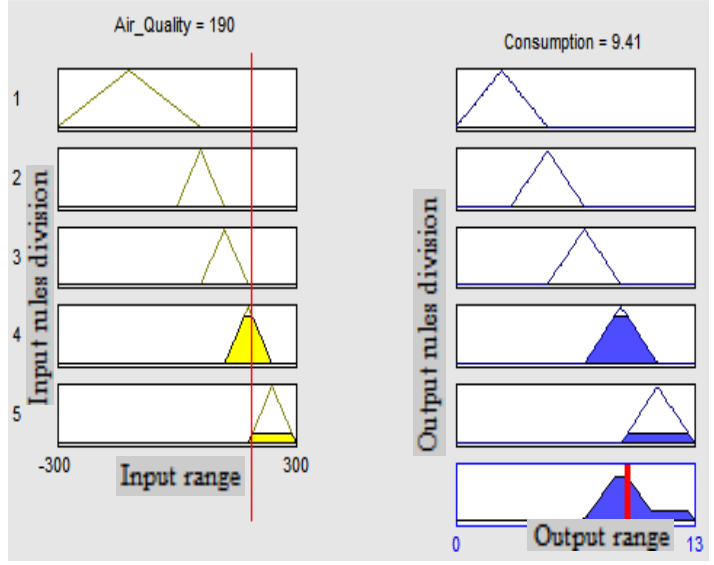

(a)

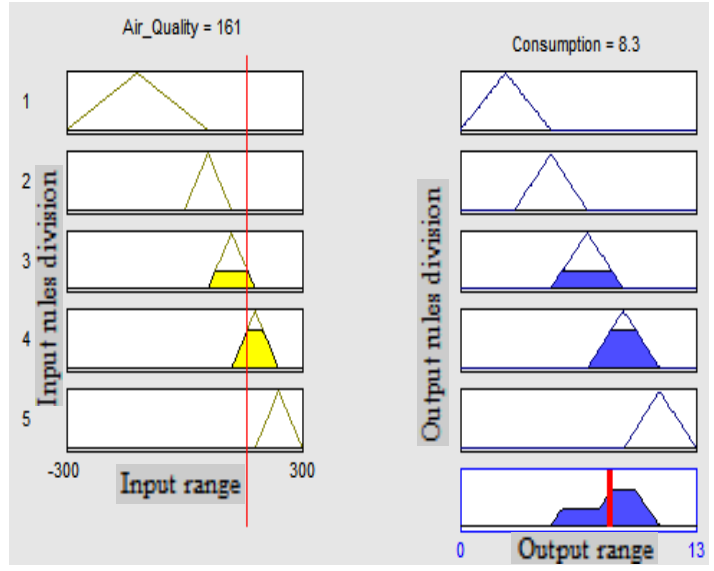

(c)

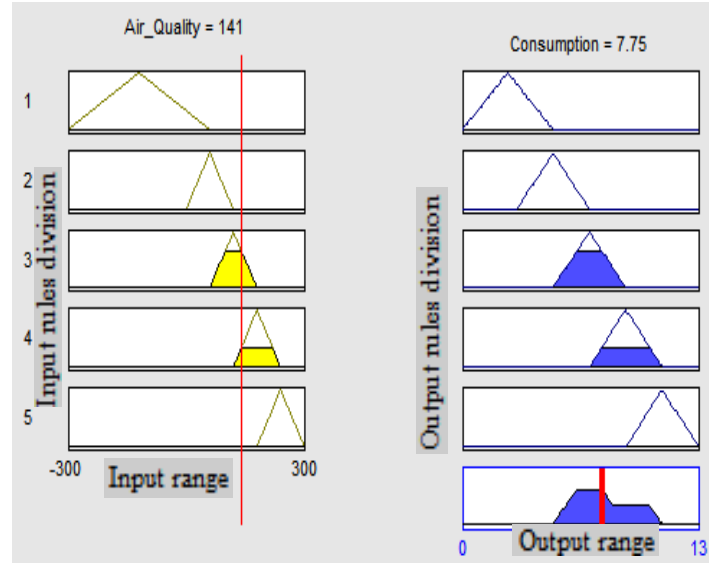

(b)

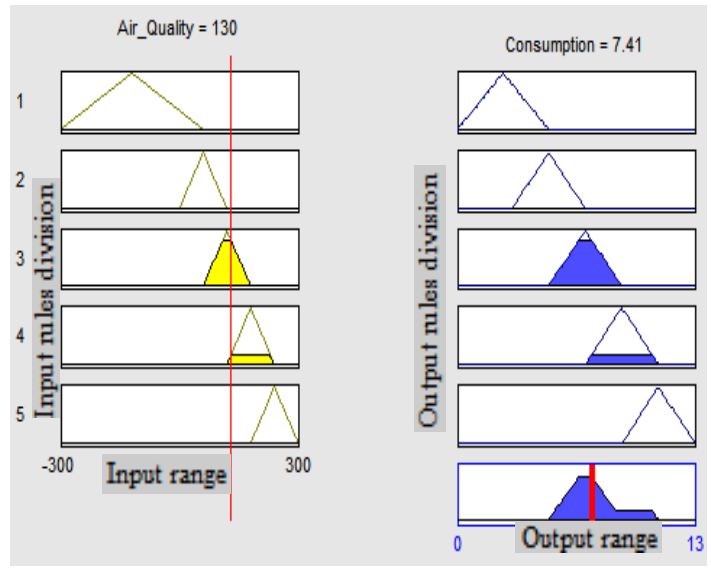

(d)

Fig. 16. Air quality fuzzy controller rule applied for a single value (a) Consumption without optimization (b) With GA optimization (c) With FA optimization (d) With prooposed approach optimization

Based on power consumed by temperature presented in Fig. 5, the power consumption of illumination shown in Fig. 9 and power consumed by ventilation system revealed in Fig. 13, the total power consumed by different optimization techniques is shown in Fig. 17. 


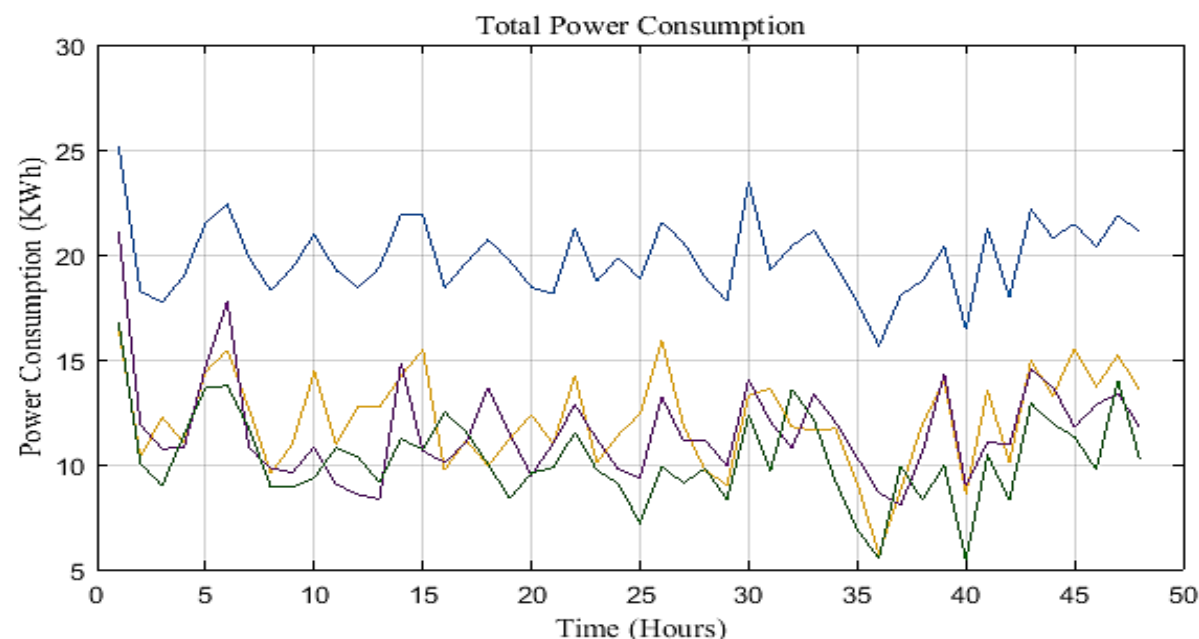

$$
\begin{aligned}
& \text { Power Consumption Without Optimization } \\
& \text { GA Optimized Power Consumption } \\
& \text { FA Optimized Power Consumption } \\
& \text { Proposed Approach Optimized Power Consumption }
\end{aligned}
$$

Fig. 17. Total power consumption observed by using different approaches

In our research work, the additional objective of the optimization algorithm is to exploit the user comfort index inside the residential building along with considering the temperature, illumination and air quality parameters. 1 is the maximum value for the comfort index whereas various approaches have been used and tested to achieve this objective. The uppermost comfort index throughout all of the hours has been pointed by the proposed approach while there exists a few overlapping with the GA and FA outputs. The lowermost comfort index has been experimented for using without optimization algorithm. The comfort index computed for different approaches is shown in Fig. 18.

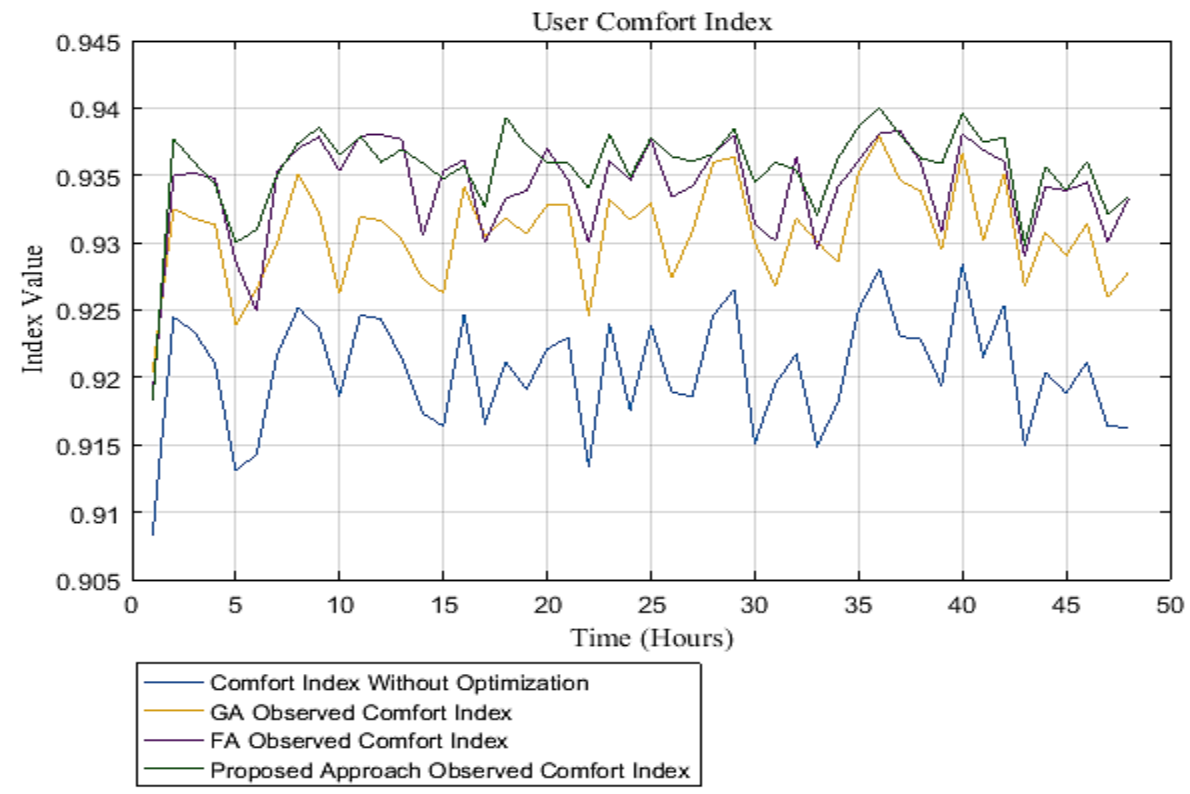

Fig. 18. Comfort Index calculated 


\section{Statistical Analysis}

Table 5 presents the statistical evidences for the power consumption and user comfort index that is achieved for all the comparative approaches. Fig. 5, Fig. 9, Fig. 13, Fig. 17 and Fig. 18 contains all the experimental data that is used for comparative analysis between the proposed appraoch and other comaprative appraoches. Table 5 presents all the evidences that the proposed approach achieved the lowest range for overall power consumption including temperature, illumination and air quality in addition with the achievement of highest user comfort. The results also clearly shows the variation in the output of comparative approaches in term of power consumption and user comfort.

Table 5. Statistical analysis of considered approaches

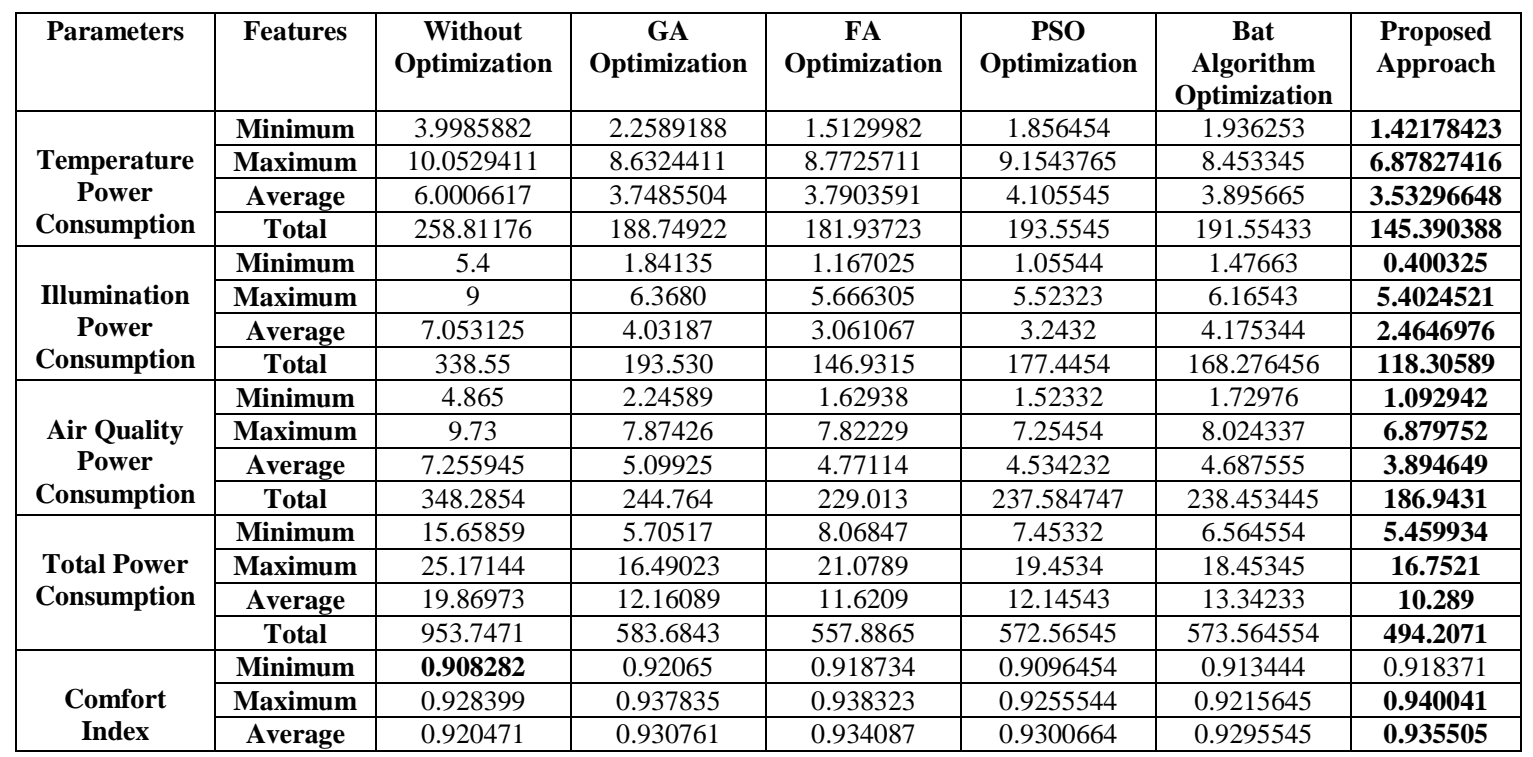

\section{Conclusion}

This research work has addressed the problem of increasing user comfort and decreasing power consumption in smart buildings using hybrid of FA and GA optimization algorithm with fuzzy controller. The step by step architecture of the proposed approach is based on various components comprising of environmental parameters (illumination, temperature and air quality), FA-GA optimizer, fuzzy controllers, comfort index, coordinator and different types of actuators. Environmental parameters (illumination, temperature, and air quality) along with user set parameters (temperature, illumination and air quality) are the input arguments to FA-GA optimizer. The outputs of the FA-GA optimizer are the optimized ranges for illumination, temperature, and air quality. The inputs to the fuzzy controllers are the environmental parameters and the FA-GA optimized parameters and the outputs of the fuzzy controllers are the lowest power essential to adjust the environment in a maching to user preferences. The coordinator calculates the total power required sent by the fuzzy controller and checks the availability of required power. The grades of the actuators are updated rendering to this power recommended by the fuzzy controllers. Using the proposed appraoch the highest user comfort index has been achived with the lowest power consumption. 


\section{Acknowledgement}

The authors would like to express the deepest appreciation to Universiti Tun Hussein Onn Malaysia and Ministry of Education Malaysia, for funding this project through Fundamental Research Grant Scheme (FRGS vote numbers 1524).

\section{References}

[1] Costa A, Keane M M, Torrens J I and Corry E, "Building operation and energy performance: Monitoring analysis and optimization toolkit,” Appld Engy, 101, 310-316, 2013. Article (CrossRef Link)

[2] Paris B, Eynard J, Grieu S and Polit M, "Hybrid PID-fuzzy control scheme for managing energy resources in buildings,” Appld Sft Cmptng, 11(8), 5068-5080, 2011. Article (CrossRef Link)

[3] Ali S and Kim D H, “Optimized Power Control Methodology Using Genetic Algorithm,” Wrls prsnl com, 83(1), 493-505, 2015. Article (CrossRef Link)

[4] Ali S and Kim D H, "Effective and comfortable power control model using Kalman filter for building energy management,” Wrls prsnl com., 73(4), 1439-1453, 2013. Article (CrossRef Link)

[5] Wang Z, Yang R and Wang L, "Multi-agent control system with intelligent optimization for smart and energy-efficient buildings," in Proc. of IECON 2010-36th Annual Conference on IEEE Industrial Electronics Society, pp. 1144-1149, 2010. Article (CrossRef Link)

[6] Dounis A I and Caraiscos C, "Advanced control systems engineering for energy and comfort management in a building environment-A review,” Rnwbl Sstnbl Engy Rvws, 13(6-7), 1246-1261, 2009. Article (CrossRef Link)

[7] Wang Z, Yang R and Wang L, "Multi-agent intelligent controller design for smart and sustainable buildings," in Proc. of Systems Conference, 2010 4th Annual IEEE, pp. 277-282, 2010.

[8] Emmerich S J and Persily A K, State-of-the-art review of CO2 demand controlled ventilation technology and applicatio, Diane Publishing, 2001. Article (CrossRef Link)

[9] Levermore G J, Building energy management systems: an application to heating and control:, E \& FN Spon, 1992.

[10] Benard C, Guerrier B and Rosset-Louè̀rrat M M, "Optimal building energy management: Part II control,” J. slr engy engg, 114(1), 13-22, 1992. Article (CrossRef Link)

[11] Curtiss P S, Kreider J and Shavit G, "Neural networks applied to buildings--A tutorial and case studies in prediction and adaptive control," American Society of Heating, Refrigerating and Air-Conditioning Engineers, Inc., Atlanta, GA (United States), 1996.

[12] Kolokotsa D, Stavrakakis G, Kalaitzakis K and Agoris D, "Genetic algorithms optimized fuzzy controller for the indoor environmental management in buildings implemented using PLC and local operating networks,” Engg Applns of AI, 15(5), 417-428, 2002.

Article (CrossRef Link)

[13] Kusiak A, Li M and Zhang Z, “A data-driven approach for steam load prediction in buildings,” Appld Engy, 87(3), 925-933, 2010. Article (CrossRef Link)

[14] ÅirokÃ J, Oldewurtel F, Cigler J A and PrÃ-vara S, "Experimental analysis of model predictive control for an energy efficient building heating system," Appld Engy, 88(9), 3079-3087, 2011. Article (CrossRef Link)

[15] Wang Z, Wang L, Dounis A I and Yang R, "Multi-agent control system with information fusion based comfort model for smart buildings,” Appld Engy, 99, 247-254, 2012.

Article (CrossRef Link)

[16] Bluyssen P M, Aries M and Dommelen P V, "Comfort of workers in office buildings: The European HOPE project,” Bldng and Envrmt, 46(1), 280-288, 2011. Article (CrossRef Link) 
[17] Marino C, Nucara A and Pietrafesa M, "Proposal of comfort classification indexes suitable for both single environments and whole buildings, Bldng and Envrmt, 57, 58-67, 2012. Article (CrossRef Link)

[18] Solla M, Ismail L H and Yunus, R, "Investigation on the potential of integrating BIM into green building assessment tools,” ARPN Jrnl of Engg and Appld Sci, 11, 2412-2418, 2016.

[19] Ejaz W, Naeem M, Shahid A, Anpalagan, A and Jo, M, "Efficient energy management for the internet of things in smart cities,” IEEE Comm Mag, 55(1), 84-91, 2017. Article (CrossRef Link)

[20] Wahid F, Alsaedi A.K.Z and Ghazali R, "Using improved firefly algorithm based on genetic algorithm crossover operator for solving optimization problems,” Jrnl Intgnt \& Fzy Sys, (Preprint), vol. 36, no. 2, pp. 1547-1562, 2019. Article (CrossRef Link)

[21] Wahid F, Ghazali R and Ismail L H, "Improved Firefly Algorithm Based on Genetic Algorithm Operators for Energy Efficiency in Smart Buildings,” Arbn Jrnl for Sci and Engg, 1-21, 2019.

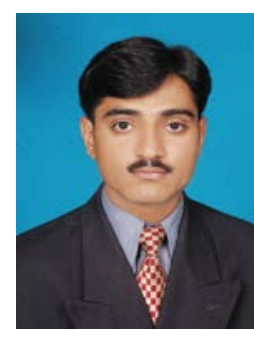

Fazli Wahid, received BS in Computer Science from University of Malakand, Pakistan in 2006, and MS in Computer Science from SZABIST, Islamabad, Pakistan in 2015. He recently completed his PhD in Information Technology from University Tun Hussein Onn Malaysia. His areas of interest are energy consumption prediction, optimization, and management using multilayer perceptron, Artificial Bee Colony, Ant Colony, Swarm Intelligence, and other Machine Learning Techniques.

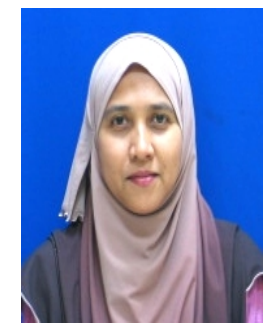

Rozaida Ghazali is currently an Associate Professor at the Faculty of Computer Science and Information Technology, Universiti Tun Hussein Onn Malaysia (UTHM). She graduated with a Ph.D. degree in Higher Order Neural Networks from the School of Computing and Mathematical Sciences at Liverpool John Moores University, United Kingdom in 2007. Earlier, in 2003 she completed her M.Sc. degree in Computer Science from Universiti Teknologi Malaysia (UTM). She received her B.Sc. (Hons) degree in Computer Science from Universiti Sains Malaysia (USM) in 1997. In 2001, Rozaida joined the academic staff in UTHM. Her research area includes neural networks, swarm intelligence, optimization, data mining, time series prediction, and data classification. She has successfully supervised a number of PhD and master students and published more than 100 articles in various international journals and conference proceedings. She acts as a reviewer for various journals and conferences. She has also served as a conference chair, and as a technical committee for numerous international conferences. 


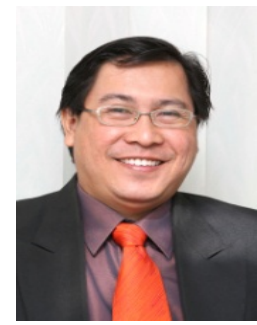

Lokman Hakim Ismail is an Associate Professor at University Tun Hussein Onn Malaysia (UTHM). He is a certified Neuro Linguistic Programming (NLP) coach and Problem Based Learning (PBL) practitioner recognised by Ministry of Higher Education Malaysia. He graduated from University of Sains Malaysia (USM) with B.Sc (Hons) in Housing, Building and Planning, majoring in Building Engineering in 1996 and University of Putra Malaysia (UPM) in 1999 for his master degree in Environment. He accomplished his PhD in architecture from the University of Liverpool, (UK) in 2007. He has held over fifteen major research grants and is the author or co-author of over fifty journal and and conference papers which focus on the sustainability of natural and built environments. He is one of the reviewer of several quarterly international journal related to Architecture, Building and Environment. His knowledge and experiences have made him achieved many immense contributions in many aspects of research.

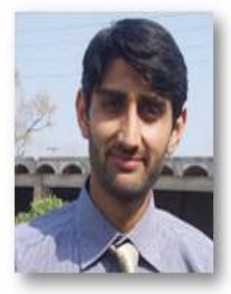

Muhammad Aamir Khan has Done bachelor in computer science from university of Peshawar Pakistan and his master from City university of science and information technology Pakistan. He had worked for two years in Xululabs LLC as data scientist. Currently he is pursuing PhD in Information technology from University Tunn Hussien Onn Malaysia. His fields of Interest are Data Science, Deep Learning and Computer Programming. 